\title{
Multiscale simulation of grain refinement induced by dynamic recrystallization of Ti6Al4V alloy during high speed machining
}

\author{
Xiang $\mathrm{Xu}^{\mathrm{a}, \mathrm{b}}$, Jun Zhang ${ }^{\mathrm{a}, *}$, José Outeiro ${ }^{\mathrm{b}, *}$, Binbin $\mathrm{Xu}^{\mathrm{a}}$, Wanhua Zhao ${ }^{\mathrm{a}}$ \\ ${ }^{a}$ State Key Laboratory for Manufacturing Systems Engineering, Xi'an Jiaotong University, Xi'an, Shaanxi, 710054, China \\ ${ }^{\mathrm{b}}$ Arts et Metiers Institute of Technology, LaBoMaP, HESAM University, Rue Porte de Paris, 71250, Cluny, France
}

\section{A R T I C L E I N F O}

Associate Editor: E Budak

Keywords:

High speed machining

Ti6Al4V

Dynamic recrystallization

Grain refinement

Finite element method

Cellular automata

\begin{abstract}
A B S T R A C T
During high speed machining (HSM), the strong thermal-mechanical coupling can lead to the microstructure evolution in the deformation zone of workpiece. Grain refinement may occur, which has great effects on the mechanical behavior, and even on the fatigue strength and corrosion resistance of the machined surface. The development of multiscale models to predict the microstructure evolution is gaining rising interest. This study aims to investigate the grain refinement induced by dynamic recrystallization (DRX) occurring in HSM of Ti6Al4V, through finite element (FE) and cellular automata (CA) methods. An orthogonal cutting model for HSM of Ti6Al4V is developed combining a modified Johnson-Cook constitutive model (TANH) and Johnson-MehlAvrami-Kolmogorov (JMAK) DRX model. The CA model is proposed considering dislocation density evolution, grain nucleation and growth. The 2D mesoscopic microstructure evolution is simulated successfully by the CA model in which the input deformation parameters come from the FE simulations of the orthogonal cutting process. Finally, the grain size and microstructure morphology calculated by both FE and CA methods are compared with those characteristics obtained experimentally by scanning electron microscopy (SEM) and transmission electron microscopy (TEM). Identical microstructure predictions from both CA and FE methods show a reasonable agreement with the TEM results, on the condition that twinning and phase transformation are not considered in the simulations. This work proves that the combination of FE and CA methods is an effective approach to achieve a more comprehensive understanding of the microstructure evolution and its effect on mechanical behavior during HSM. It shows that the rise of both DRX volume fraction and DRX grain size finally results in the slightly decreasing of average grain size of serrated chips with the increase of cutting speed, which leads to the strain softening phenomenon of flow stress.
\end{abstract}

\section{Introduction}

Predicting microstructure evolution accurately in machining process is of great significance to improve production efficiency and obtain components with high performance. A review by Pan et al. (2017) indicated that the material microstructure evolution induced by machining results from the thermal and mechanical loading process, and the altered microstructure have an inverse influence on materials flow stress behavior, machining forces and surface integrity. The development of microstructure modeling is gaining rising interest, and Arrazola et al. (2013) indicated that a constitutive model including the microstructure effects would more accurately reflect the mechanical behavior of workpiece during machining. The review presented by Melkote et al. (2017) show that several models for predicting the microstructure evolution in metal cutting using FE simulations have been proposed. It is worth to notice the limitation and accuracy of microstructure models in FE simulations is based on the phenomenological description and many microstructure parameters cannot be represented. Huang and Logé (2016) reviewed the dynamic recrystallization in metals. They show that microstructure evolution under severe plastic deformation can include dislocation density, grain deformation, grain nucleation and growth. The final microstructure morphology is strongly dependent on deformation condition. The mechanical properties are influenced by both grain size and grain morphology. Therefore, simulation methods that can improve the accuracy in predicting microstructure evolution and consider the influence on mechanical behavior in metal cutting are required.

M'Saoubi and Ryde (2005) applied the Electron Back Scattering Diffraction (EBSD) technique for characterizing the microstructure of the primary deformed zone in metal cutting. Microstructure

\footnotetext{
* Corresponding author.

E-mail addresses: junzhang@xjtu.edu.cn (J. Zhang), Jose.OUTEIRO@ensam.eu (J. Outeiro).
} 
characteristics of the deformed zone in machining several part materials have been investigated. Transmission electron microscopy (TEM) was used by Guo et al. (2011) to qualitatively analyze the deformed microstructure in machining pure $\mathrm{Cu}$. They show that the extent of grain refinement is greater induced by larger strains with a typical minimum size of $150 \mathrm{~nm}$ for pure metals. Duan and Zhang (2012) found that the adiabatic shear bands (ASBs) is consisted of fine equiaxed grains and high dislocation density, and the equiaxed grains in ASBs result from the dynamic rotational recrystallization. Xu et al. (2019) analyzed the effects of cutting speed on microstructure alteration of machined surface during high speed machining (HSM) of Ti6Al4V alloy. They found that a white layer is formed in machined surface due to the significant grain refinement during HSM. Based on the framework of deformation-microstructure correlation, several different models of grain size prediction have been developed. After Estrin and Kim (2007) proposed the dislocation density based microstructure evolution model, Ding et al. (2011) conducted FE simulations using Coupled Eulerian Lagrangian (CEL) formulation to investigate the grain size evolution of $\mathrm{Al} 6061 \mathrm{~T} 6$ alloy and OFHC Cu in cutting process. They show that low strain, high strain rate or high cutting temperature could result in a coarse and elongated grain structure. Liu et al. (2015) proposed a unified dislocation density-based model by considering dislocation drag effect at high strain rate. This model was calibrated in order to obtain a good agreement with experimental measured results from low to high cutting speeds. Physic-based microstructure models are preferred as they can reveal the materials nature of deformation and mechanical properties. However, the values of the microstructure parameters of these models are difficult to be obtained experimentally. Depending on the research of mechanism of dynamic recrystallization (DRX) in metal deformation process by Fanfoni and Tomellini (1998), two types of DRX can occur in metals: discontinuous dynamic recrystallization (DDRX) and continuous dynamic recrystallization (CDRX). Zener-Hollomon (Zener and Hollomon, 1944) and Johnson-Mehl-Avrami-Kolmogorov (JMAK) models (Fanfoni and Tomellini, 1998) are mostly used to predict grain size evolution. Rotella et al. (2013) utilized the Hall-Petch (Hall, 1951; Petch, 1953) and Zener-Hollomon models (Zener and Hollomon, 1944) developed as subroutine to predict the grain size and surface hardness in turning of AA7075 alloy. Wang et al. (2016) conducted the simulation of grain size and microhardness in chips and machined surface by combining Hall-Petch (Hall, 1951; Petch, 1953) and Zener-Hollomon equations (Zener and Hollomon, 1944) in machining Ti6Al4V. JMAK model and its application was reviewed by Fanfoni and Tomellini (1998) to successfully describe the DRX kinetics. Arisoy and Özel (2015a) utilized the JMAK model by conducting 3D FE simulation in turning of Ti6Al4V alloy to predict DRX and grain size. The results show an alteration of microstructure and grain size in machined subsurface due to DRX.

The constitutive model considering microstructure effect plays a significant role in predicting the microstructure alterations in severe plastic deformation. A shear flow stress in terms of microstructure by considering the dislocation density was proposed by Mecking and Kocks (1981). Armstrong and Zerilli (1987) developed a dislocation-based constitutive model for BCC and FCC crystalline materials including the effect of grain size and the dislocation characteristics. Estrin and Kim (2007) proposed a flow stress model considering the dislocation density at cells interior and cells walls. Imbrogno et al. (2018) investigated the deformation mechanism of Waspaloy under different cutting condition and developed a physic-based constitutive model which consists of additive long-range and short-range contributions. In metal cutting simulations the Johnson-Cook (JC) constitutive model is often modified to include the microstructure effects. Andrade et al. (1994) proposed a modified JC model for describing the effect of DRX on the mechanical behavior of OFHC copper. Denguir et al. (2017) developed a JC model included the term of DRX proposed by Andrade et al. (1994) and the stress state term proposed by Bai and Wierzbicki (2008) to describe the mechanical behavior of OFHC copper. This model was used in the FE orthogonal cutting simulation to predict the surface integrity. After Calamaz et al. (2008) proposed a modified JC model (called TANH) which included the strain softening effect, Sima and Özel (2010) summarized the issue of flow softening and DRX, and proposed a modification to TANH model, which has been used by other researchers to predict adiabatic shearing in machining.

Due to the simplification of microstructure predicting model in FE, many microstructure parameters cannot be included to study the effect of microstructure evolution on plastic deformation mechanism. Although microstructure predicting model in FE has been successful applied to obtain the dislocation density and grain size distributions, these models cannot describe the grain refinement evolution and final microstructure characteristics. This microstructure evolution can be described by using the dislocation density evolution model established by Goetz and Seetharaman (1998). Using this model, Cellular automata (CA) method has been used to simulate the grains nucleation and growth process induced by DRX, under large plastic deformation in mesoscale. Ding and Guo (2001) studied the DRX phenomenon of OFHC copper under low strain rate thermomechanical processing. They proposed a theoretical model of grain nucleation, grain growth and grain boundary migration. CA method has been applied successfully to simulate the DRX process for titanium alloys by Song et al. (2014). Therefore, the CA method is suitable to conduct simulations of microstructure evolution during thermomechanical processing in mesoscale. Shen et al. (2017) is probably the first one to investigate the microstructure evolution in machining process using CA method. However, since then, few studies have continued to use this method for studying the microstructure of the cutting process.

The literature review described above shows that previous works are mostly focused on the use of the microstructure-based constitutive models in FE simulation to investigate the microstructure evolution in metal cutting at macroscale. The obvious shortcoming of these models is that they cannot reproduce the grain structure at mesoscale or even microscale. Moreover, very few research on the simulation of the microstructure evolution in metal cutting by multiscale methods are available in the literature. Therefore, the aim of this study is to propose a multiscale simulation approach to predict the grain refinement induced by DRX during HSM of Ti6Al4V.

In this paper, a FE model using a user subroutine VUHARD of ABAQUS/Explicit is developed firstly based on the TANH constitutive model and JMAK DRX model (Fanfoni and Tomellini, 1998). The accuracy of FE machining model is validated by comparing the predicted and measured cutting force and chip geometry. CA model considering dislocation density evolution, grain nucleation and growth is established to calculate the 2D mesoscopic microstructure evolution, in which the input deformation parameters comes from the FE simulations. The grain size distribution and microstructure morphology are calculated by conducting FE and CA simulation. Finally, the results of microstructure characteristics in simulation are compared with experimental results measured by scanning electron microscopy (SEM) and transmission electron microscopy (TEM) to verify the accuracy of predicting microstructure for FE and CA model.

\section{Experimental orthogonal cutting tests}

To compare the results obtained from the FE simulations and experiments, a five-axis DMG MORI milling center, model DMU 50, was used to carry out the orthogonal cutting tests. As shown in Fig. 1, the thickness and width of workpiece were $3 \mathrm{~mm}$ and $20 \mathrm{~mm}$, respectively. The diameter of the face milling cutter was $80 \mathrm{~mm}$ and up milling was used to conduct high speeds orthogonal cutting. A feed per tooth of $0.1 \mathrm{~mm} / \mathrm{z}$ was applied and the axis of the cutter was parallel to the left edge of workpiece. Uncoated cemented carbide inserts Sandvik N 331.1A having the same geometry of FE model were used. In order to ensure that tool wear was not affecting the machining tests results, the total cutting length was reduced $(100 \mathrm{~mm})$ and new tool cutting edges 
(a)
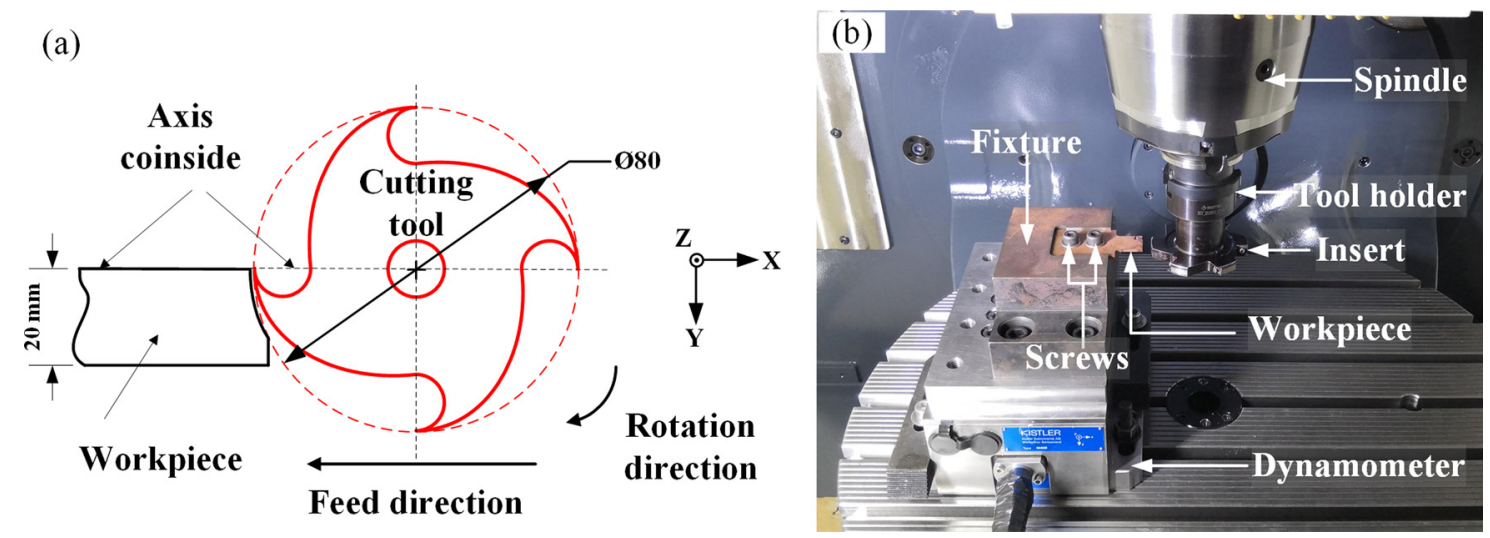

Fig. 1. (a) Schematic and (b) experimental setup of orthogonal cutting tests.

were used at each test. Cutting forces were obtained using Kistler dynamometer, model 9265B. And then the chips were inserted into conductive mosaic materials as samples. All samples were metallurgically treated by grinding, polishing, and etching with $1 \mathrm{ml} \mathrm{HF}+6 \mathrm{ml} \mathrm{HNO}_{3}$ $+193 \mathrm{ml} \mathrm{H}_{2} \mathrm{O}$ solution and observed by SEM. Cross-section samples in shear band of chips were prepared by using Focused Ion Beam (FIB). The FEI Tecnai G2 F20 S-TWIN microscope at $200 \mathrm{KV}$ was adopted to conduct TEM testing.

\section{FE orthogonal cutting model of microstructure evolution in HSM}

\subsection{Orthogonal cutting model}

A 2D FE model of orthogonal cutting of Ti6Al4V titanium alloy was developed, as shown in Fig. 2. This model is composed by a workpiece and tool. The workpiece is divided into three parts: the uncut chip layer; the sacrificial layer and the remain part of the workpiece. The sacrificial layer is a thin layer of elements that will be removed during the simulation, to allow the separation of material and from the workpiece to form the chip. This separation occurs when the cumulative plastic strain in the elements of this sacrificial layer reach the equivalent plastic strain of damage initiation, as described in section 3.2.2. The thickness of the sacrificial layer depends of several factors including the value of the cutting edge radius, and should be kept as small as possible in order to minimize the material volume lost. This model was simulated using FE and Lagrangian formulation in ABAQUS/ Explicit FEA software. A dynamic coupled temperature-displacement analysis step was adopted. The uncut chip thickness was $0.1 \mathrm{~mm}$ and the cutting width was $3 \mathrm{~mm}$, respectively. The cutting speed was selected from $250 \mathrm{~m} / \mathrm{min}$ to $500 \mathrm{~m} / \mathrm{min}$. Cemented tungsten carbide cutting tools were used, having a rake angle of $0^{\circ}$, a clearance angle of $15^{\circ}$ and a cutting edge radius of $10 \mu \mathrm{m}$. In machining practice, the maximum recommended cutting speed for machining of Ti6Al4V titanium alloy using cemented carbide tool is about $120 \mathrm{~m} / \mathrm{min}$. For higher cutting speed such as those speeds used in this research work, polycrystalline diamond (PCD) is the best tool material for machining of Ti6Al4V titanium alloy. However, to generate significant dynamic recrystallization in the chip, high temperatures are required. Therefore, uncoated cemented carbide tools were selected for this study since they generate higher temperatures in the deformation zone when compared to the PCD tools. This is due to the combination of lower thermal conductivity ( $50 \mathrm{~W} / \mathrm{m} \mathrm{K}$ for cemented carbide and $450 \mathrm{~W} / \mathrm{m} \mathrm{K}$ for PCD) and higher friction coefficient ( 0.3 for cemented carbide (Courbon et al., 2014) and 0.27 for PCD (Davim et al., 2008)) of the cemented carbide tools when compared to the PCD tools. Table 1 shows the thermal, physical and mechanical properties of both workpiece and tool.

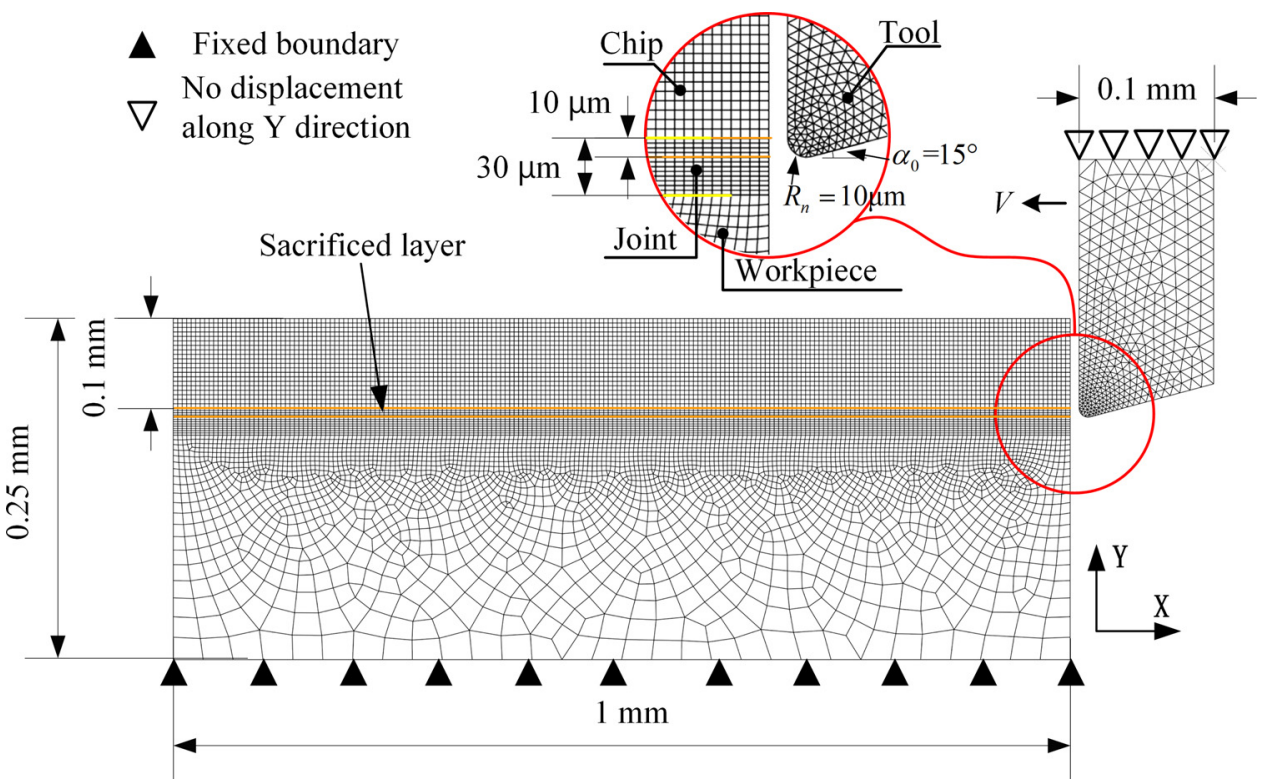

Fig. 2. Orthogonal cutting model and corresponding boundary conditions. 
Table 1

Material properties of the workpiece and cutting tool.

\begin{tabular}{|c|c|c|c|c|c|c|}
\hline Material & Density $\left(\mathrm{kg} \mathrm{m}^{-3}\right)$ & Elastic modulus (GPa) & Poisson's ratio & Specific heat $\left(\mathrm{J} \mathrm{kg}^{-1} \mathrm{~K}^{-1}\right)$ & Thermal conductivity $\left(\mathrm{W} \mathrm{m}{ }^{-1} \mathrm{~K}^{-1}\right.$ ) & Thermal expansion $\left(\mathrm{K}^{-1}\right)$ \\
\hline WC & 11900 & 534 & 0.22 & 400 & 50 & - \\
\hline Ti6Al4V & 4430 & 109 & 0.34 & 611 & 6.8 & $10^{-5}$ \\
\hline
\end{tabular}

Table 2

Material parameters of modified JC constitutive model.

\begin{tabular}{|c|c|c|c|c|c|c|c|c|c|c|c|c|c|}
\hline Material & $A(\mathrm{MPa})$ & $B(\mathrm{MPa})$ & $n$ & C & $m$ & $a$ & $b$ & $d$ & $r$ & $s$ & $T_{m}\left({ }^{\circ} \mathrm{C}\right)$ & $T_{r}\left({ }^{\circ} \mathrm{C}\right)$ & $\dot{\varepsilon}_{0}(/ \mathrm{s})$ \\
\hline Ti6Al4V & 782.7 & 498.4 & 0.28 & 0.028 & 1 & 2 & 5 & 1 & 2 & 0.05 & 1620 & 20 & $10^{-5}$ \\
\hline
\end{tabular}

The workpiece was meshed using the planar quadrilateral continuum elements (CPE4RT) with four-node, plane strain, reduced integration features, which is suitable for large deformation analysis. The tool was meshed as three-node linear displacement and temperature elements (CPE3T) with plane strain feature. The meshing method of the workpiece and tool directly determines the convergence of the calculation process and has a great impact on the calculation results. In order to be closer to the actual workpiece geometry, the mesh approach shown in Fig. 2 is adopted. Zhang et al. (2011) proposed to gradually reduce the mesh size until the cutting force becomes close to the experimental results. Besides that, Miguélez et al. (2013) concluded that the width of adiabatic shear band is highly dependent on mesh size. The simulations with different mesh sizes have been conducted and the width of adiabatic shear band is $10.2 \mu \mathrm{m}, 7.7 \mu \mathrm{m}, 5.5 \mu \mathrm{m}$ and $4.8 \mu \mathrm{m}$ for mesh size of $10 \mu \mathrm{m}, 8 \mu \mathrm{m}, 5 \mu \mathrm{m}$ and $3 \mu \mathrm{m}$, respectively. When the mesh size is lower than or equal to $5 \mu \mathrm{m}$, the width of adiabatic shear band does not change. By this way, the mesh size in the uncut chip layer was determined as $5 \mu \mathrm{m}$ and the mesh size in sacrificial layer was set finer as $2.5 \mu \mathrm{m}$. Besides that, the mesh size of tool in tool-chip contact zone was set less than that of workpiece. The workpiece and tool were set with an initial temperature of $20^{\circ} \mathrm{C}$.

As for the boundary conditions of the orthogonal cutting model, the following assumptions are established: (1) the tool is set as a rigid body and the displacement or vibration of the tool in Y-direction is zero; (2) the uncut chip thickness remains stable; (3) materials properties of the model is set as isotropic. The bottom of the workpiece is fixed and the tool is moving along the X-direction only, from right to left at a constant cutting speed.

The contact model has noticeable impact on the mechanical and temperature response of the cutting model, thus in the microstructure evolution. The stick-slip friction contact model proposed by Zorev (1963) is used. This model is used to represent the tool-chip contact, divided into two regions: sticking friction is the contact behavior nearby the cutting edge and sliding friction occurs far away from the cutting edge. The Zorev (1963) contact model can be represented as following:

$\tau_{f}=\left\{\begin{array}{lll}\tau_{Y}, & \mu \sigma_{n} \geq \tau_{Y} & \text { (sticking region) } \\ \mu \sigma_{n}, & \mu \sigma_{n} \geq \tau_{Y} & \text { (sliding region) }\end{array}\right.$

where $\mu$ is the Coulomb friction coefficient. $\sigma_{n}$ is the normal stress. The yield shear stress, $\tau_{Y}$, is calculated with the estimated yield stress, and given by $\tau_{Y}=\sigma_{Y} / \sqrt{3}$.

\subsection{Constitutive model}

\subsubsection{Flow stress model}

In order to describe the dynamic mechanical response in HSM, an accurate and reliable constitutive model is of great importance. HSM belongs to a severe plastic deformation process with high strain rate and temperature, especially for the chip formation. Therefore, considering the strain softening induced by DRX, the modified JC material constitutive model called TANH developed by Sima and Özel (2010) is adopted. The constitutive model can be described as:

$\sigma=\left(A+B \varepsilon^{n}\left(\frac{1}{\exp \left(\varepsilon^{a}\right)}\right)\right)\left(1+C \ln \frac{\dot{\varepsilon}}{\dot{\varepsilon}_{0}}\right)\left(1-\left(\frac{T-T_{r}}{T_{m}-T_{r}}\right)^{m}\right)$

$\times\left(D+(1-D)\left(\tanh \left(\frac{1}{(\varepsilon+p)^{r}}\right)\right)^{s}\right)$

where $D=1-\left(\frac{T}{T_{m}}\right)^{d}$ and $p=\left(\frac{T}{T_{m}}\right)^{b}$

$\sigma$ is the flow stress, $\varepsilon$ is the equivalent plastic strain, $\dot{\varepsilon}$ is the equivalent plastic strain rate, $\dot{\varepsilon}_{0}$ is the reference strain rate, $T_{r}$ and $T_{m}$ are the room and melting temperature, respectively. $A, B, C, n, m, a, b$, $d, r$ and $s$ are the constitutive model coefficients. These coefficients of Lee and Lin (1998) and Sima and Özel (2010) are adopted to match the machining deformation condition and given in Table 2 . They are verified by comparing the experimental and simulated cutting force in the following. The stress-strain curves for the modified JC constitutive model are shown in Fig. 3 calculated for temperature of $600^{\circ} \mathrm{C}$ and $800^{\circ} \mathrm{C}$ and variable strain rate from $10^{3}$ to $10^{5} / \mathrm{s}$.

\subsubsection{Damage model and separation criterion}

During HSM of Ti6Al4V, adiabatic shear bands and serrated chips are produced because of the high strain rate and low thermal conductivity. The high shear localization in thin bands will culminate in crack initiation and propagation. Moreover, a separation process occurs when a layer of material is removed from the bulk workpiece to form the chip. To reach this separation, the material must be deformed until the fracture. Therefore, the constitutive model also needs to include damage behavior. In this study, JC damage model (Johnson and Cook, 1985) and an energetic-based ductile fracture criterion is applied, in which two stages, i.e. damage initiation and damage evolution, are included.

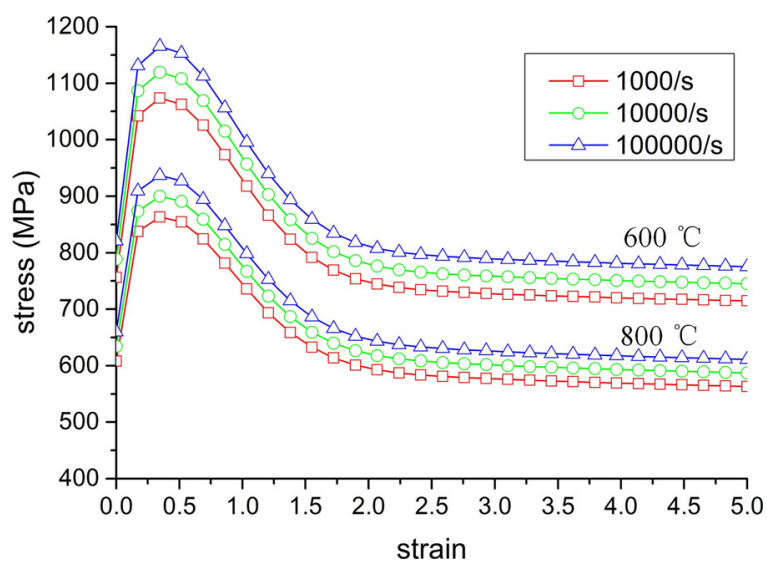

Fig. 3. Stress-strain curves of modified JC constitutive model at $600^{\circ} \mathrm{C}$ and $800^{\circ} \mathrm{C}$ and variable strain rate from $10^{3}$ to $10^{5} / \mathrm{s}$. 
Table 3

Coefficients of the JC damage model of Ti6Al4V.

\begin{tabular}{lllll}
\hline$D_{1}$ & $D_{2}$ & $D_{3}$ & $D_{4}$ & $D_{5}$ \\
\hline-0.09 & 0.25 & -0.5 & 0.014 & 3.87 \\
\hline
\end{tabular}

The damage initiation is described by the variable $w$, which is defined as:

$w=\sum \frac{\Delta \bar{\varepsilon}^{p l}}{\bar{\varepsilon}_{0}^{p l}}$

where $\bar{\varepsilon}_{0}^{p l}$ is the equivalent plastic strain of damage initiation, $\Delta \bar{\varepsilon}^{p l}$ is equivalent plastic strain increment. $\bar{\varepsilon}_{0}^{p l}$ is calculated by the following equation, which is related to stress triaxiality, strain rate and temperature:

$\bar{\varepsilon}_{0}^{p l}=\left[D_{1}+D_{2} \exp \left(D_{3} \frac{\sigma_{p}}{\bar{\sigma}}\right)\right]\left[1+D_{4} \ln \left(\frac{\dot{\bar{\varepsilon}}}{\dot{\bar{\varepsilon}}_{0}}\right)\right]\left[1+D_{5} \frac{T-T_{r}}{T_{m}-T_{r}}\right]$

where parameters $D_{1} \sim D_{5}$ are the coefficient for the JC damage model. The values of the coefficients were determined by Johnson and Cook (1985) and Sun and Guo (2009), and given in Table 3.

As shown in Fig. 4, $w$ increases continuously with plastic deformation, and when $w$ reaches a critical value of 1 , damage evolution is activated. In the stage of damage evolution, the fracture energy is obtained by integrating this yield stress in function of the strain and it can be described as:

$G_{f}=\int_{\bar{\varepsilon}_{0}^{p l}}^{\bar{\varepsilon}_{f}^{p l}} L \sigma_{y} d \bar{\varepsilon}^{p l}=\int_{0}^{\bar{u}_{f}^{p l}} \sigma_{y} d \bar{u}^{p l}$

where $L$ is the characteristic length, $\bar{u}^{p l}$ is equivalent displacement and $\bar{u}_{f}^{p l}$ is equivalent displacement at failure.

According to Mabrouki et al. (2008), the fracture energy $G_{f}$ can be estimated from the fracture toughness, $K_{C}$ :

$G_{f}=\left(\frac{1-v^{2}}{E}\right) K_{C}^{2}$

The stiffness degradation of materials in condition of damage evolution can be described by variable $D$, and when $D$ increase from $0-1$, the complete fracture is occurring.

$D=\frac{L \bar{\varepsilon}}{\bar{u}_{f}^{p l}}=\frac{\bar{u}}{\bar{u}_{f}^{p l}}$

where the equivalent displacement $\bar{u}=L \bar{\varepsilon}$ and equivalent displacement at failure $\bar{u}_{f}^{p l}=\frac{2 G_{f}}{\sigma_{y 0}}$.

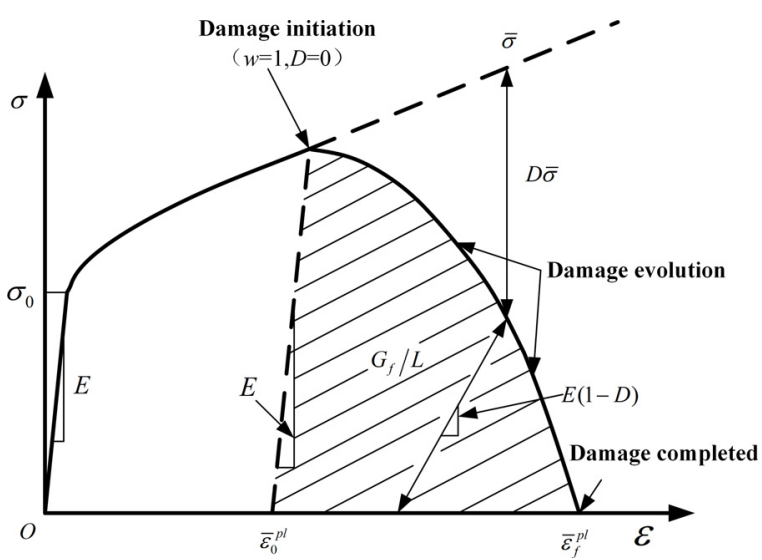

Fig. 4. Stress-strain curve of material damage degradation.

\subsubsection{Grain size prediction model}

During HSM, the plastic deformation and heat generation result in microstructure evolution, especially severe plastic deformation results in grain refinement and DRX by thermal activation. Increasing the cutting speed, plastic strain, strain rate and temperature increase, while the time of thermal conduction decreases rapidly, which has significant influence on microstructure evolution. JMAK DRX model (Fanfoni and Tomellini, 1998) was implemented in a VUHARD Fortran subroutine to predict the grain size distribution in machining metals using ABAQUS/ Explicit FEA software. This model is represented by Eqs. (8)-(12). DRX is activated when the strain reaches the critical strain, $\varepsilon_{c}$, defined by the following equation:

$\varepsilon_{c}=a_{1} d_{0}^{h_{1}} \dot{\varepsilon}^{m_{1}} \exp \left(Q_{1} / R T\right)+c_{1}$

where $a_{1}, h_{1}, m_{1}$ and $c_{1}$ are material parameters, $R$ is gas constant, $Q_{1}$ is current activation energy.

The review performed by Fanfoni and Tomellini (1998) indicates that JMAK model is widely accepted for predicting grain size evolution which includes the effects of initial grain size, strain, strain rate and temperature. Based on the theory proposed by Zener and Hollomon (1944), the evolution of DRX volume fraction and DRX grain size due to grain nucleation and growth process would be calculated.

The DRX volume fraction $X_{\text {drex }}$ presented by Avrami (1940) for dynamic recrystallization is defined as follows:

$X_{\text {drex }}=1-\exp \left[-\beta_{d}\left(\frac{\varepsilon-a_{10} \varepsilon_{p}}{\varepsilon_{0.5}}\right)^{k_{d}}\right]$

where $\beta_{d}$ and $k_{d}$ are material constant, $\varepsilon_{0.5}$ is the value of strain with the DRX volume fraction of 0.5 , and its formula is shown as:

$\varepsilon_{0.5}=a_{5} d_{0}^{h_{5}} \varepsilon^{n_{5}} \dot{\varepsilon}^{m_{5}} \exp \left(Q_{5} / R T\right)+c_{5}$

where $a_{5}, h_{5}, n_{5}, m_{5}$ and $c_{5}$ are material parameters. After the DRX volume fraction is obtained, the corresponding DRX grain size is the size of new formed grains after nucleation and growth process of DRX, which is calculated as follows:

$d_{\text {drex }}=a_{8} d_{0}^{h_{8}} \varepsilon^{n_{8}} \dot{\varepsilon}^{m_{8}} \exp \left(Q_{8} / R T\right)+c_{8}$

Similarly, $a_{8}, h_{8}, n_{8}, m_{8}$ and $c_{8}$ are material parameters. Finally, the average grain size is the average value of the remaining original grain size and new formed DRX grain size, which can be calculated by:

$d=d_{0}\left(1-X_{\text {drex }}\right)+d_{\text {drex }} X_{\text {drex }}$

where the initial grain size $d_{0}$ is $8 \mu \mathrm{m}$, initial DRX volume is 0 . The coefficients of JMAK model (Fanfoni and Tomellini, 1998) for Ti6Al4V are given in Table 4. They were extracted from the Pan et al. (2016) and Wang et al. (2016) research works.

To predict the DRX kinetics and grain size, a user subroutine VUHARD is developed in FORTRAN by using JMAK model (Fanfoni and Tomellini, 1998). The flowchart of the calculating process of user subroutine VUHARD is shown in Fig. 5.

\section{CA model of microstructure evolution in HSM}

High plastic strain and rapid temperature increasing will occur in primary deformation zone in HSM, which could result in the dislocation density evolution. Dislocation density is generally regarded as the power for grain deformation, nucleation and growth of DRX process under thermomechanical processing. Work hardening from the severe plastic deformation will induce generation of dislocation tangles and result in the increasing of dislocation density. On the other hand, the inhabitation of dislocation would result in the rapid drop of dislocation density by the influence of dynamic recovery (DRV) softening in high temperature condition. The dislocation density evolution and hardening behavior are determined by the interaction of these two processes. The DRX process will be activated when dislocation density 
Table 4

JMAK model coefficients of Ti6Al4V.

\begin{tabular}{|c|c|c|c|c|c|c|c|c|c|}
\hline Peak strain & $\begin{array}{l}a_{1} \\
0.0064\end{array}$ & $\begin{array}{l}h_{1} \\
0\end{array}$ & & $\begin{array}{l}m_{1} \\
0.0801\end{array}$ & $\begin{array}{l}Q_{1}\left(\mathrm{~J} \mathrm{~mol}^{-1}\right) \\
30579\end{array}$ & $\begin{array}{l}c_{1} \\
0\end{array}$ & $\begin{array}{l}a_{2} \\
0.8\end{array}$ & & \\
\hline \multirow[t]{2}{*}{ DRX kinematics } & $a_{5}$ & $h_{5}$ & $n_{5}$ & $m_{5}$ & $Q_{5}\left(\mathrm{~J} \mathrm{~mol}^{-1}\right)$ & $c_{5}$ & $a_{10}$ & $\beta_{d}$ & $k_{d}$ \\
\hline & 0.022 & 0 & 0 & 0.11146 & 26430 & 0 & 0.0311 & 0.9339 & 0.5994 \\
\hline \multirow[t]{2}{*}{ DRX grain size } & $a_{8}$ & $h_{8}$ & $n_{8}$ & $m_{8}$ & $Q_{8}\left(\mathrm{~J} \mathrm{~mol}^{-1}\right)$ & $c_{8}$ & & & \\
\hline & 1280 & 0 & 0 & -0.088 & -36848 & 0 & & & \\
\hline
\end{tabular}

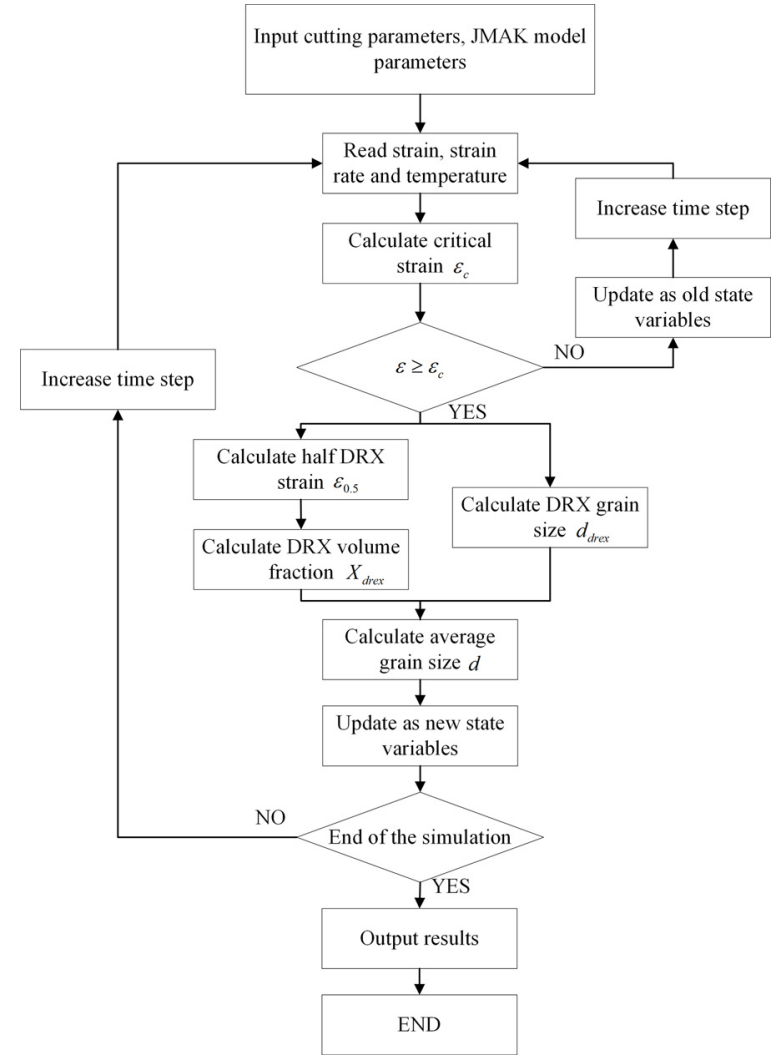

Fig. 5. Flowchart of subroutine VUHARD using JMAK model.

reaches the critical value, which is significantly dependent on temperature and strain rate.

\subsection{Model of dislocation density evolution}

Dislocation density $\rho$ under the influence of work hardening and DRV process is proposed by Mecking and Kocks (1981) (KM model), and it can be calculated as following,

$\frac{d \rho}{d \varepsilon}=k_{1} \sqrt{\rho}-k_{2} \rho$

where $k_{1}$ is related to the work hardening and $k_{2}$ to the DRV. Both $k_{1}$ and $k_{2}$ are temperature and strain rate dependent, and expressed by,

$k_{1}=c_{1} \dot{\varepsilon}^{m} \exp \left(\frac{m Q}{R T}\right)$

$k_{2}=c_{2} \dot{\varepsilon}^{-m} \exp \left(-\frac{m Q}{R T}\right)$

where $c_{1}$ is a reference constant related to work hardening, $c_{2}$ is a reference constant related to DRV, $m$ is the constant related to strain rate sensitivity, $R$ is the gas constant, $Q$ is the activation energy. An initial dislocation density, $\rho_{0}$, of the material is assumed to be uniform and nucleation of dDRX starts when it reaches the critical value. Littlewood et al. (2011) measured the dislocation density with $10^{12} / \mathrm{m}^{2}$ of undeformed Ti6Al4V alloy, which was applied in this study. For the new recrystallization grains, the dislocation density evolves from initial dislocation density.

\subsection{Model of DRX nucleation and growth}

The nucleation rate $\dot{n}$ of $\mathrm{dDRX}$ depends on both the temperature $T$ and the strain rate $\dot{\varepsilon}$, and can be represented as follows:

$\dot{n}=C \dot{\varepsilon}^{m} \exp \left(-\frac{Q}{R T}\right)$

which is proposed by Kugler and Turk (2004), where $C$ is a material constant. Considering the energy change, the critical dislocation density $\rho_{c}$ of grain boundary is described by Ding and Guo (2001), which can be expressed as follows,

$\rho_{c}=\left(\frac{20 \gamma_{m} \dot{\varepsilon}}{3 b M l \tau^{2}}\right)^{1 / 3}$

where $l$ is the dislocation mean free path, $M$ is the mobility of grain boundary, $\gamma_{m}$ is the grain boundary energy, and $\tau$ is the dislocation line energy given by:

$\tau=c \mu b^{2}$

where $\mu$ is the shear modulus, $b$ is the Burger's vector and $c$ is a material constant of 0.5 .

The dislocation mean free path $l$ is represented by Roberts and Ahlblom (1978) expression as,

$\frac{\sigma l}{\mu b}=G$

where $G$ is a constant, for which 10 is adopted for most metals (Ding and Guo, 2002).

The flow stress $\sigma$ is a function of the dislocation density component, and calculated using the following equation (Mecking and Kocks, 1981):

$\sigma=\alpha \mu b \sqrt{\rho}$

Dislocation density of a DRX grain and the original microstructure are generally different, which provide the growth driving force of a DRX grain with reduction of grain storage energy. The grain growth velocity $V_{i}$ of the current DRX grain is assumed directly proportional to the mobility of the boundary and driving force per cell (Qian and Guo, 2004), thus given by,

$V_{i}=\frac{M F_{i}}{4 \pi r_{i}^{2}}$

where $r_{i}$ represents the grain radius of the current DRX grain. The mobility of grain boundary $M$ is given by Stüwe and Ortner (1974),

$M=\frac{\delta D_{b} b}{K T} \exp \left(-\frac{Q_{b}}{R T}\right)$

where $K$ is Boltzmann's constant, $\delta$ is the characteristic grain-boundary thickness, $D_{b}$ is the boundary self-diffusion coefficient, $Q_{b}$ is the boundary-diffusion activation energy.

The e driving force $F_{i}$ of the newly formed DRX grains is generated 
from the surface energy reduction proposed by Ding and Guo (2004),

$F_{i}=4 \pi r_{i}^{2} \tau\left(\rho_{m}-\rho_{d}\right)-8 \pi r_{i} \gamma$

where $\gamma$ represents the grain boundary energy, which is derived from the grains misorientation, $\rho_{m}$ and $\rho_{d}$ are the dislocation density of the original grain and DRX grain.

Considering the effects of time step and cell size, the nucleation probability $P$ in the CA model is described by the following equation:

$P=\dot{n} \times \Delta t \times S_{C A}$

where $S_{C A}$ is the area of a CA cell. Current CA cells are assumed to be square, so $S_{C A}=L_{C A}{ }^{2}$, where $L_{C A}$ was the length of a CA cell.

The current grain size is calculated as,

$d_{i}=\sqrt{\frac{4 N_{i} a^{2}}{\pi}}$

where $N_{i}$ is the lattice number that makes up the current grain, $a$ is the lattice size. Considering the Hall-Petch relation (Hall, 1951; Petch, 1953) between material strength and grain size, with the decreasing of grain size, the intense distribution of grain boundary with high energy induces the increasing of material strength, which makes grains harder to refine. According to Ding and Guo (2002) and Song et al. (2014), the values of the CA model coefficients for the Ti6Al4V are list in Table 5.

\subsection{Description of CA simulation}

Based on the above theoretical model of DRX, a routine has been developed in MATLAB under the premise of CA transformation rules. Fig. 6 shows the initial grain distribution obtained by a natural grain growth algorithm based on the lowest energy principle ( $\mathrm{He}$ et al., 2006). The total energy is provided by the grain boundary in the CA space, and the energy of the interfacial cells depends on the number of the same state of central cell and neighboring cells. The driving force for the natural grain growth is derived from the reduction of the interfacial energy by state transition. The crystal structure of grains is hexagonal close packed (HCP) with average grain size of $8 \mu \mathrm{m}$ measured by SEM. Different colors represent grains with different orientations.

CA simulation of microstructure evolution is conducted with the increasing of strain, in which time step is $\Delta t=\varepsilon /(N \dot{\varepsilon})$, where $N$ is the total iteration step and 300 steps are adopted in this study. During each time step, the whole lattice space is searched, and related judgement and calculation are carried out to update the lattice state at the next step. The above step loop in every step until the predetermined strain is achieved. After that, the results of dislocation density, grain size, grain distribution and DRX characteristics will be output. The flowchart of CA simulation is shown in Fig. 7. Five variables were assigned to each CA cell were selected to control the cell state during CA simulation: (1) dislocation density corresponds to the energy generated by thermal deformation, (2) grain orientation is used to distinguish different grains, (3) mark of grain boundary is used to identify whether the cell is on grain boundary, (4) mark of DRX represents the cell undergo the DRX process, (5) index of color is used to display grain characteristics distribution. CA simulation of microstructure evolution depends on the state transformation of each cell in CA domain which depends on its previous state and neighboring cells' sate. According to CA transformation rules, every CA cell has three probabilities to transform: (1)

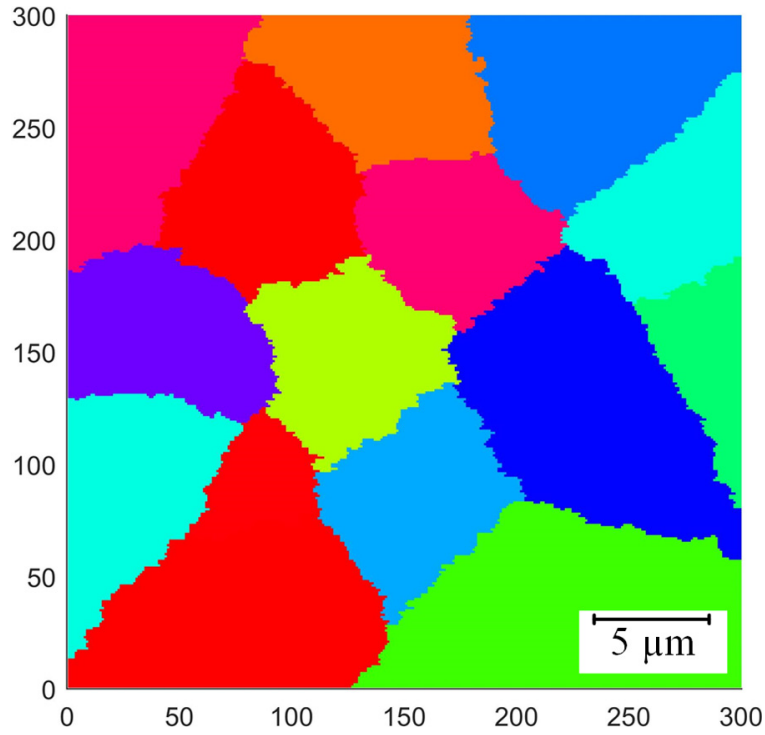

Fig. 6. Initial microstructure generated by a natural grain growth algorithm.

grain nucleation, (2) grain growth and (3) keep the previous state, as shown in Fig. 8. At the beginning of every simulation step, the dislocation density in whole CA domain was updated firstly based on the deformation condition calculated from FEM. And then the dislocation density was judged whether it exceed the critical value. If so a random number between $0-1$ was generated along the grain boundary and when it was lower than the DRX nucleation probability, the cell was transformed to be a new DRX grain cell with updated state variables. It's worth noting that the priority of grain nucleation is set higher than grain growth, which means that if a grain nucleation process of a cell has been satisfied, grain growth process was ignored by default. As for the grain growth process, the following several conditions need to be satisfied: (1) the cell is located at grain boundary, (2) the driving force of neighboring DRX grain is positive, (3) the migration distance of grain boundary is greater than cell size, (4) randomly generated number is smaller than transformation probability $(p=i / 4)$ where $i$ represents the number of cells with same orientation. If any condition of grain nucleation and growth cannot be matched, state variables of the cell would keep as the previous with continuous increasing dislocation density.

\section{Results and discussion}

\subsection{Validation of FE orthogonal cutting and CA models}

To verify the accuracy of the FE machining model, the cutting force and chip morphology obtained from simulation and experiments under different cutting speeds were compared. When analyzing the experimental cutting force, the stable periods of each tooth cutting process were selected to calculate the average cutting forces. The average and standard deviation values of the simulated and experimental cutting force were calculated from 5 tests peer cutting condition, as shown in Table 6. It can be summarized that cutting forces obtained by simulation is slightly larger than those of experiments, and the difference is within the reliable range. The difference between average simulated

Table 5

Material parameters of CA model.

\begin{tabular}{|c|c|c|c|c|c|c|c|c|}
\hline Parameter & $K_{1}$ & $K_{2}$ & $Q\left(\mathrm{~kJ} \mathrm{~mol}^{-1}\right)$ & $m$ & $R\left(\mathrm{~J} \mathrm{~mol}^{-1} \mathrm{~K}^{-1}\right)$ & $C$ & $\mu_{0}(\mathrm{MPa})$ & $b(\mathrm{~m})$ \\
\hline Value & $3.4 \times 10^{9}$ & 5.2 & 153 & 0.848 & 8.314 & $4 \times 10^{13}$ & $2.05 \times 10^{4}$ & $2.86 \times 10^{-10}$ \\
\hline Parameter & $G$ & $\delta D_{b}\left(\mathrm{~m}^{3} \mathrm{~s}^{-1}\right)$ & $K\left(\mathrm{~m}^{2} \mathrm{~kg} \mathrm{~s}^{-2} \mathrm{~K}^{-1}\right)$ & $Q_{b}\left(\mathrm{~kJ} \mathrm{~mol}^{-1}\right)$ & $\rho_{0}\left(/ \mathrm{m}^{2}\right)$ & $\alpha$ & $\nu$ & $\theta_{m}(\mathrm{rad})$ \\
\hline Value & 10 & $5 \times 10^{-15}$ & $1.38 \times 10^{-23}$ & 108 & $10^{12}$ & 0.5 & 0.34 & $\pi / 12$ \\
\hline
\end{tabular}




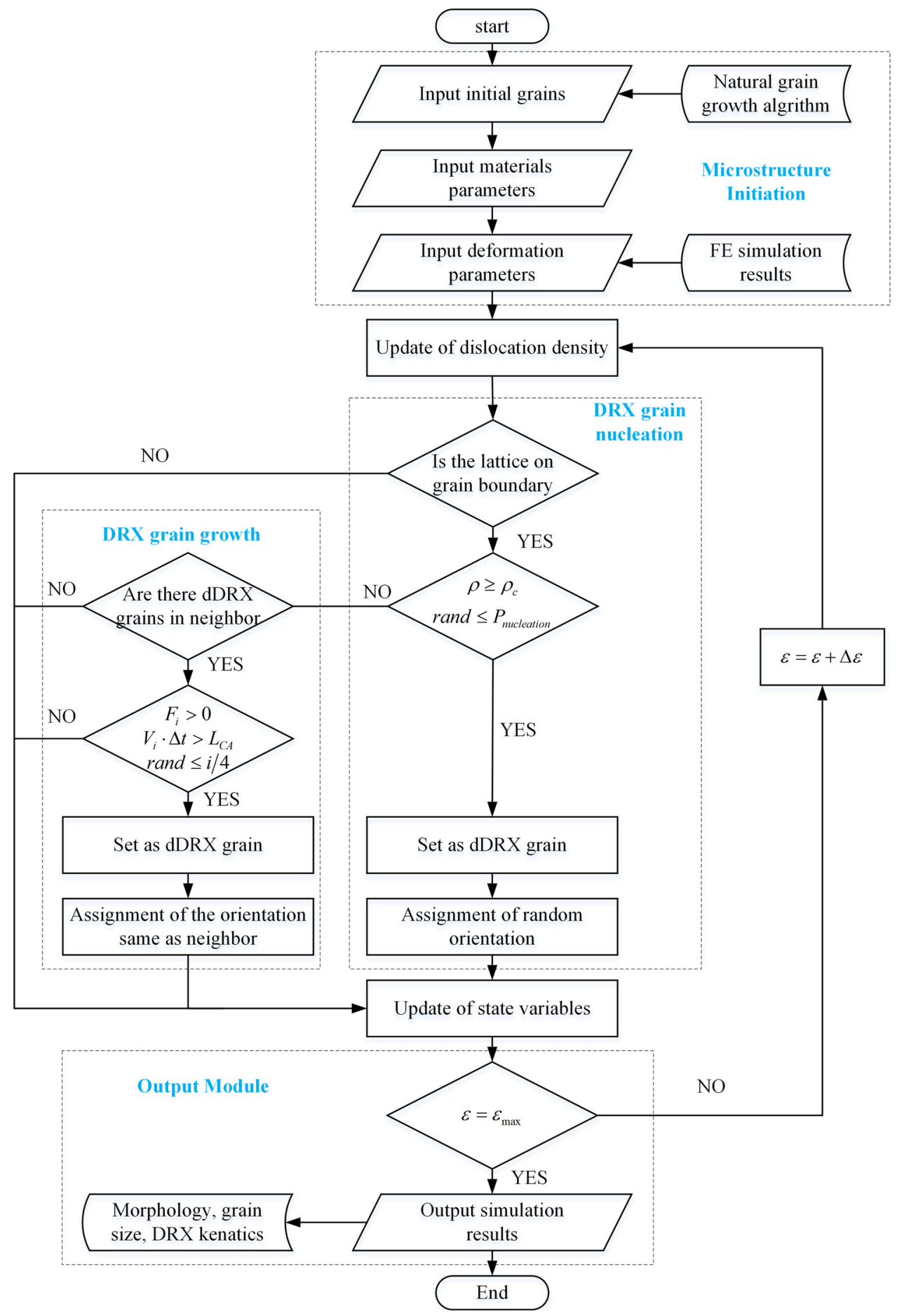

Fig. 7. Flowchart of CA simulation.

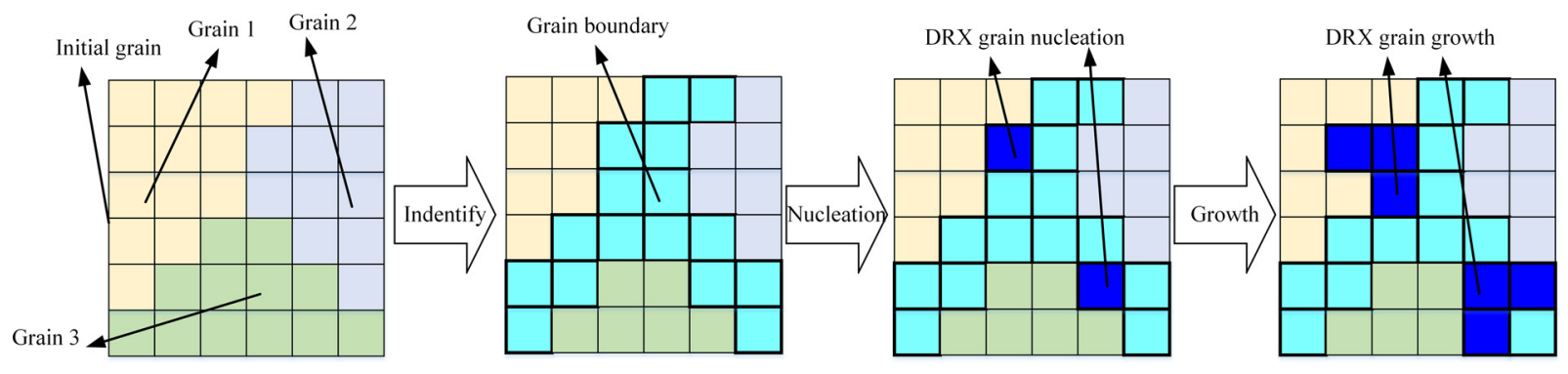

Fig. 8. The schematic diagram of state transformation process during CA simulation. 
Table 6

Comparison of simulated and experimental cutting force.

\begin{tabular}{|c|c|c|c|c|}
\hline \multirow[t]{2}{*}{ Cutting speed } & \multirow{2}{*}{$\begin{array}{l}\text { Simulated force } F_{t} \\
(\mathrm{~N}) \\
\text { Average }\end{array}$} & \multicolumn{2}{|c|}{ Experimental force $F_{t}(\mathrm{~N})$} & \multirow[t]{2}{*}{ Difference } \\
\hline & & Average & $\begin{array}{l}\text { Standard } \\
\text { deviation }\end{array}$ & \\
\hline$V_{c}=250 \mathrm{~m} / \mathrm{min}$ & 535.4 & 512.1 & 24.7 & $4.5 \%$ \\
\hline$V_{c}=500 \mathrm{~m} / \mathrm{min}$ & 524.8 & 480.6 & 32.1 & $9.2 \%$ \\
\hline
\end{tabular}

and experimental cutting force is less than $10 \%$.

The serrated chips geometry obtained from simulation and experiments is shown in Fig. 9, and the morphology and structure of these serrated chips show similar characteristics. As for detailed features, the peak, valley, spacing and the width of adiabatic shear band (ASB) of serrated chips, which are noted in Fig. 9, are the commonly used typical characteristics proposed by Sutter and List (2013) and Molinari et al. (2002) for quantifying serrated chips dimension and the statistical results with multiple sampling and averaging are listed in Table 7 . The difference of the peak, valley and spacing value of serrated chips between simulated and experimental results are within $30 \%$. By the above comparison, the deformation parameters and temperature calculated based on this FE machining model are considered to be reliable.

Fig. 10 shows the microstructure characteristics of the shear band of serrated chips obtained experimentally by Transmission Electron Microscopy (TEM) and simulated by CA model. Fine grains through DRX were observed in Fig. 10 (b) and (f), and the grain morphology and size vary with the deformation conditions at different cutting speeds. As shown in Fig. 10 (d) and (h), the simulated microstructure shows a reasonable agreement with experimental observed one. Besides that, deformed and elongated grains and twins were also observed in TEM images, which also could be formed at high strain rates, which according to the FE simulation it can reaches $10^{5} / \mathrm{s}$. As a result, the TEM observed grain size was about $0.3-0.4 \mu \mathrm{m}$, which was smaller than CA simulated results of about $0.8-0.9 \mu \mathrm{m}$, since continuous DRX (cDRX) mechanism and twin formation theory were not included in this model. As shown in Fig. 11, the research work of Dargusch et al. (2018) and Xu et al. (2019) shows that the twinning is formed in chips and machined surface, which could have direct influence on grain refinement and mechanical response. In general, this CA model was verified feasibly to predict DRX behavior of serrated chips in machining process, while a more accurate CA model considering the effect of cDRX, twinning and phase transformation behavior is expected to be developed in the future to predict the grain refinement of multiphase materials.

\subsection{Multiscale simulation of grain refinement by combining FE and CA methods}

The average grain size distribution simulated by FE and the grain morphology simulated by CA method are shown in Fig. 12. The simulated results and computational characteristics indicates that $\mathrm{FE}$ method is better at calculating speed and displaying the grain size distribution in different regions of workpiece in macroscale, while CA method is preferable to visualize the microstructure morphology at a certain point, which can reproduce the physical process of grain evolution and help to study the effect of microstructure evolution on mechanical behavior. The DRX kinetics results and average grain size simulated by FE and CA method are listed in Table 8. The results showed

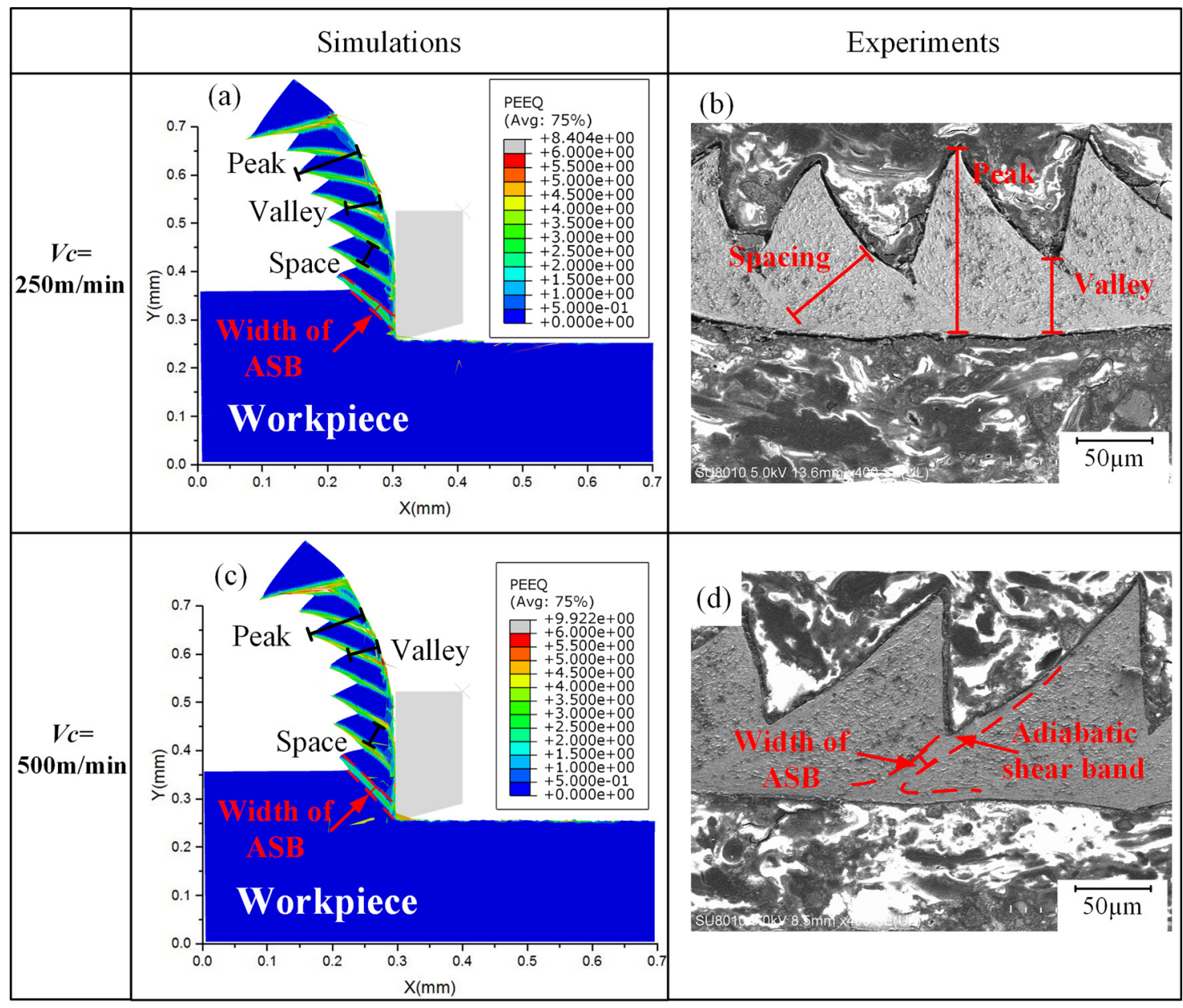

Fig. 9. The simulated equivalent strain (a and c) and SEM image of serrated chips (b and d) at $250 \mathrm{~m} / \mathrm{min}$ and $500 \mathrm{~m} / \mathrm{min}$. 
Table 7

Comparison of chip morphology between simulation and experimental tests.

\begin{tabular}{|c|c|c|c|c|c|c|c|c|}
\hline & \multicolumn{4}{|c|}{$V_{c}=250 \mathrm{~m} / \mathrm{min}$} & \multicolumn{4}{|c|}{$V_{c}=500 \mathrm{~m} / \mathrm{min}$} \\
\hline & Peak $(\mu \mathrm{m})$ & Valley $(\mu \mathrm{m})$ & Spacing $(\mu \mathrm{m})$ & Width of ASB $(\mu \mathrm{m})$ & Peak $(\mu \mathrm{m})$ & Valley $(\mu \mathrm{m})$ & Spacing $(\mu \mathrm{m})$ & Width of ASB $(\mu \mathrm{m})$ \\
\hline Simulation & 141.5 & 80.8 & 60.2 & 5.9 & 128.3 & 73.7 & 62.7 & 6.5 \\
\hline Experimental & 158.8 & 64.8 & 86 & 5.5 & 145.5 & 61.9 & 76.7 & 5.7 \\
\hline Difference & $10.9 \%$ & $24.7 \%$ & $30 \%$ & $6.8 \%$ & $11.8 \%$ & $19.1 \%$ & $18.3 \%$ & $12.3 \%$ \\
\hline
\end{tabular}

a reasonable agreement between these two methods.

As mentioned by Arrazola et al. (2013), the main difficulty of the development of microstructure evolution model is the determination of the microstructure parameters. However, the development of advanced material testing technology like the EBSD, permitted to further investigate the grain refinement mechanism (Liao et al., 2019). It's worth noting that the results of CA simulation can be compared with the materials testing results (e.g., TEM and EBSD) from experiments directly and its spatial scale is on mesoscale, so it is only suitable for exploring local microstructures evolution at present. As shown in Fig. 12 (a) and (c), the average grain size distribution of whole chip can be obtained from the FE simulation. In addition, the grain morphology in the selected point is presented in Fig. 12 (b) and (d). Compared to the single FE simulations of orthogonal cutting with microstructure evolution model, the implementation of CA model makes it possible to lead a direct comparison between simulation and materials testing results. Therefore, the combination of the FE subroutine and CA model in this study can achieve a more comprehensive and multiscale understanding of the microstructure evolution of machining and its influence on the cutting process.

\subsection{Grain refinement mechanism induced by DRX process during HSM of Ti6Al4V}

The simulated strain, strain rate and temperature in serrated chips at $250 \mathrm{~m} / \mathrm{min}$ and $500 \mathrm{~m} / \mathrm{min}$ are displayed in Fig. 13. It shows that the strain, strain rate and temperature of adiabatic shear band in chips at $500 \mathrm{~m} / \mathrm{min}$ are higher than those generated at $250 \mathrm{~m} / \mathrm{min}$. Based on JMAK dynamic recrystallization model (Fanfoni and Tomellini, 1998), the distribution of DRX volume, DRX grain size and average grain size at cutting speed of $250 \mathrm{~m} / \mathrm{min}$ and $500 \mathrm{~m} / \mathrm{min}$ were obtained and shown in Fig. 14. The recrystallization behavior only occurs in the region of shear band and secondary deformation zone, which corresponding to the adiabatic shear of titanium alloy and friction between tool and chip respectively. From the DRX volume distribution in Fig. 14 (a) and (d), it can be deduced that the DRX volume fraction of shear band in chips at cutting speed of $500 \mathrm{~m} / \mathrm{min}$ is higher than that of $250 \mathrm{~m} / \mathrm{min}$. And the DRX grain size of shear band at $500 \mathrm{~m} / \mathrm{min}$ is also slightly bigger than that of $250 \mathrm{~m} / \mathrm{min}$ which is shown in Fig. 14 (b) and (e). With increasing of cutting speed, the rise of both DRX volume fraction and DRX grain size finally leads to the decreasing of average grain size as Fig. 14 (c) and (f). From Eqs. (9) and (11), the DRX behavior is closely related to the strain, strain rate and temperature.

Seen from Fig. 14, there are differences of the value of DRX volume fraction, DRX grain size and average grain size between different areas of the same shear band. In order to analyze the cause of these differences, three points are selected to compare the deformation parameters: point 1 close to the free surface, point 2 middle area, point 3 close to tool-chip contact area in shear band of chips. As shown in Fig. 14 (a) and (b), along the path from point 1 to point 3 , the DRX volume fraction increases gradually, while the DRX grain size decreases, which corresponding to the increasing of strain, strain rate and temperature in Fig. 13 (a)-(c). This phenomenon occurs because DRX behavior is based on thermal activation theory, so the DRX process can be fully completed only when the temperature exceeds the recrystallization temperature and lasts for a certain time and strain reaches a critical value. Higher strain rates enhance grain nucleation and inhibit grain growth, which relusts in smaller DRX grain size.

During cutting process, the DRX volume fraction will firstly increase, and then gradually become stable. The occurrence of adiabatic shear leads the strain in shear band to increase sharply and then decrease, which can be devided into two stages of loading and unloading. In the period of loading, the DRX is actived by large strain and high temperature, and the heterogeneous distribution of them in different
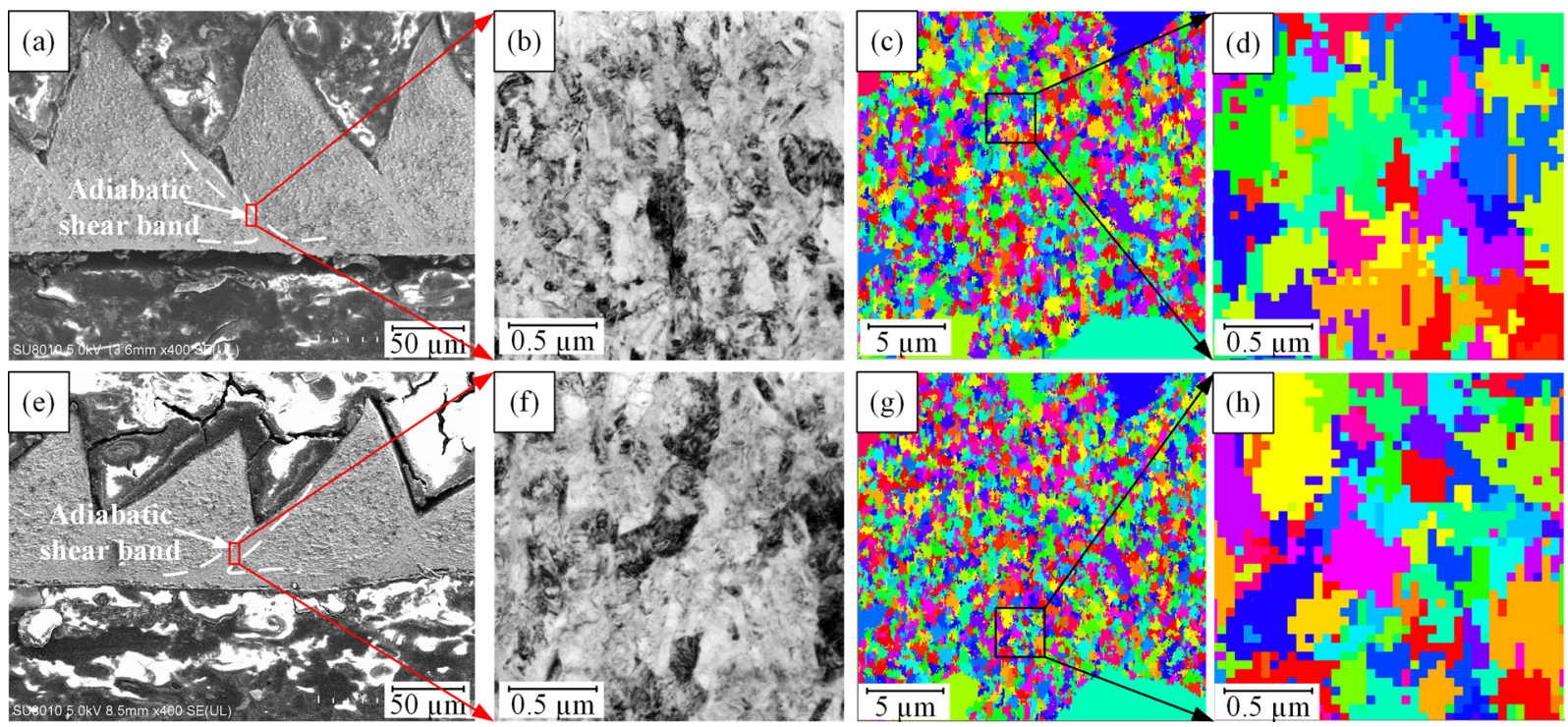

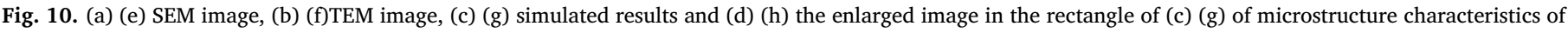
serrated chips at cutting speed of $250 \mathrm{~m} / \mathrm{min}$ and $500 \mathrm{~m} / \mathrm{min}$ respectively. 

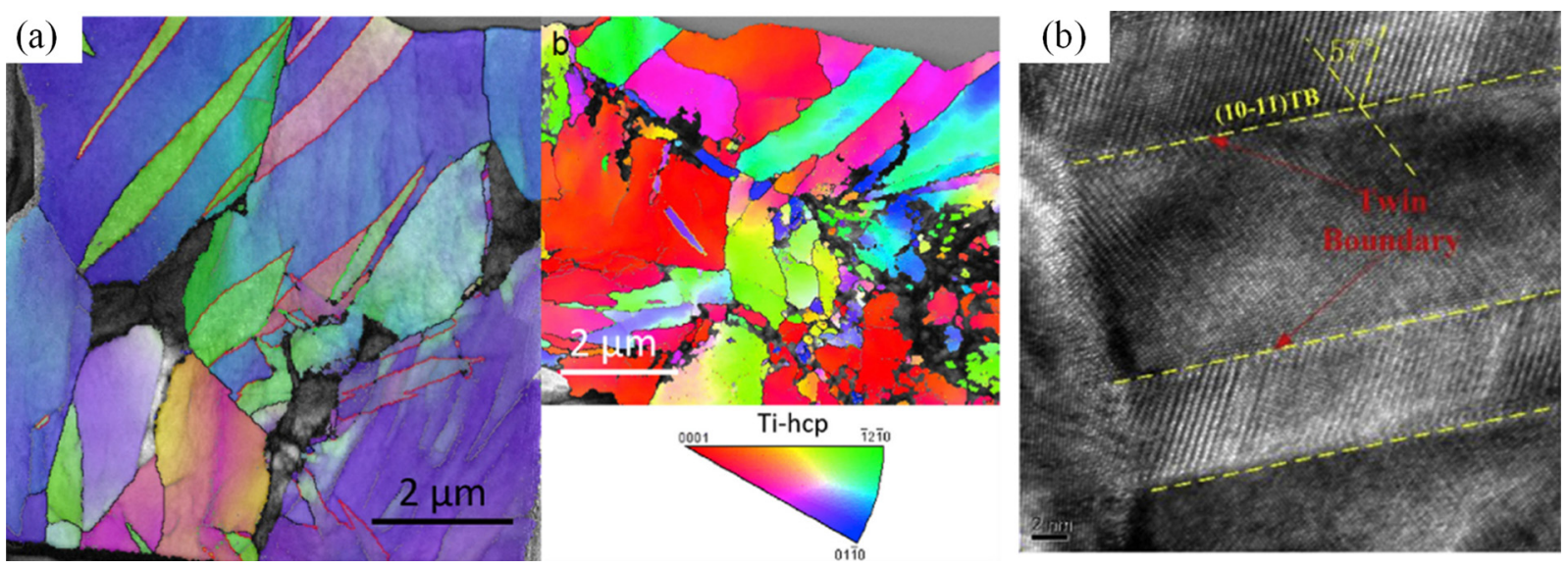

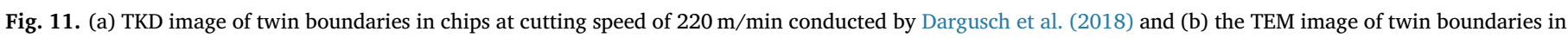
machined surface at cutting speed of $250 \mathrm{~m} / \mathrm{min}$ conducted by Xu et al. (2019) during machining Ti6Al4V.
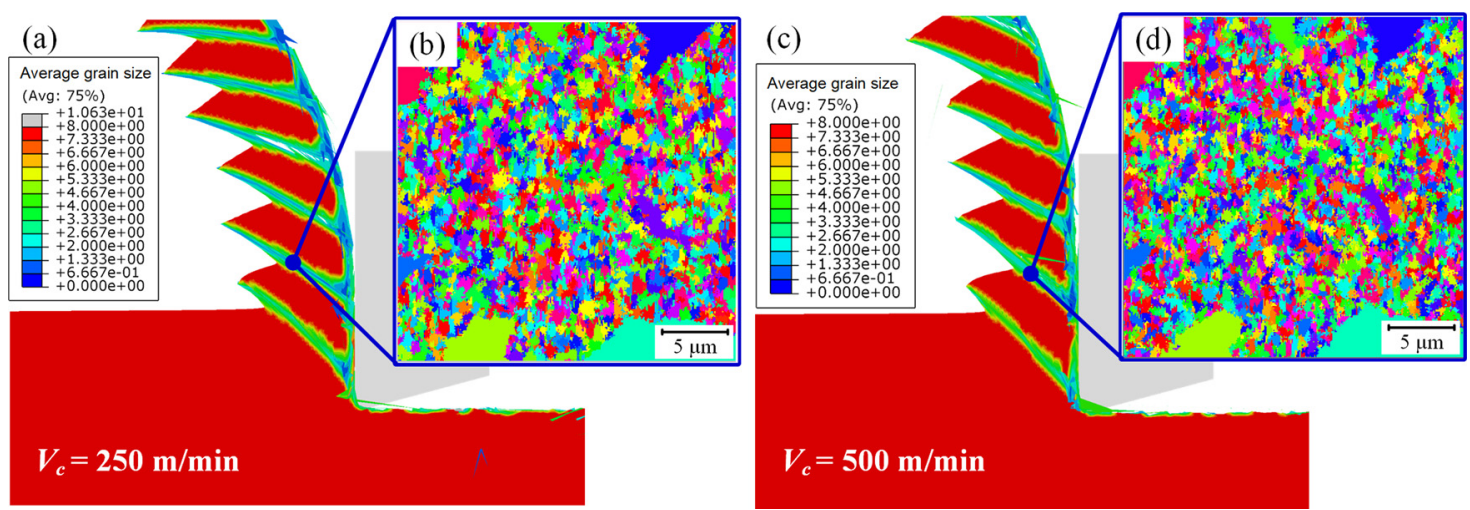

Fig. 12. Average grain size distribution simulated by FE (a and c) and the grain morphology simulated by CA method (b and d) at cutting speed of $250 \mathrm{~m} / \mathrm{min}$ (a and b) and $500 \mathrm{~m} / \mathrm{min}$ (c and d).

regions is the essence for the differemce of DRX volume fraction and grain size. During unloading, temperature without the effect of plastic strain leads grains to a state of dynamic recovery, in which DRX volume fraction will decrease. When temperature decreases to a certain value, the microstructure evolution gradually weakens until it reaches a stable state.

In order to compare the changes of DRX kenetics caused by cutting speed, point 2 in Fig. 14 (a) is selected and the peak values of strain, strain rate, temperature and DRX kinetics are listed in Table 9. All of strain, strain rate and temperature rise with cutting speed increasing from $250 \mathrm{~m} / \mathrm{min}$ to $500 \mathrm{~m} / \mathrm{min}$. Higher temperature is benefit for DRX behavior so that DRX volume fraction is higher at $500 \mathrm{~m} / \mathrm{min}$. The growth of DRX grain size is derived from higher temperature and longer growing time, and higher temperature and strain rate at $500 \mathrm{~m} / \mathrm{min}$ eventually produce DRX grains with slightly greater size. Finally, lower average grain size of $1.18 \mu \mathrm{m}$ is produced at $500 \mathrm{~m} / \mathrm{min}$ compared to $1.33 \mu \mathrm{m}$ at $250 \mathrm{~m} / \mathrm{min}$. The deformation condition provides the input parameters for CA simulation and the results of DRX kinetics are compared with CA results.

\subsection{Effect of grain refinement on the mechanical behavior and microhardness}

The flow stress curve and corresponding microstructure morphology at cutting speed of $250 \mathrm{~m} / \mathrm{min}$ are shown in Fig. 15. Only DRX grains are displayed in simulated microstructure morphology in which white region represents the original microstructure. The flow stress curve shows a typical DRX trend in which the strain softening phenomenon is obvious. Due to the microstructure morphology in strain of 1.1, the DRX grain nuclei begins to form at grain boundaries, and the strain hardening rate slows down when the lower dislocation density of DRX grains is introduced into the whole domain. With the increasing of strain to 2.2, the rise of DRX grains volume fraction and grain size results in the decrease of flow stress which is called strain softening effect. From the microstructure morphology in strain of 3.4 , it is found that when the DRX grains grow to a certain size, the new DRX grain nuclei are formed at the previous DRX grain boundaries which cause grain size to a critical value. The continuous increasing of strain leads to DRX grains become dominant, and then the DRX grain size trend to become

Table 8

Comparison of the DRX volume fraction, DRX grain size and average grain size between FE and CA simulations.

\begin{tabular}{|c|c|c|c|c|c|c|}
\hline & \multicolumn{3}{|l|}{$V_{\mathrm{c}}=250 \mathrm{~m} / \mathrm{min}$} & \multicolumn{3}{|l|}{$V_{\mathrm{c}}=500 \mathrm{~m} / \mathrm{min}$} \\
\hline & DRX volume fraction & DRX grain size $(\mu \mathrm{m})$ & Average grain size $(\mu \mathrm{m})$ & DRX volume fraction & DRX grain size $(\mu \mathrm{m})$ & Average grain size $(\mu \mathrm{m})$ \\
\hline FE Simulation & 0.82 & 0.93 & 1.33 & 0.91 & 1.07 & 1.18 \\
\hline CA Simulation & 0.86 & 0.92 & 1.12 & 0.89 & 0.86 & 1.06 \\
\hline Difference & $4.7 \%$ & $5.1 \%$ & $18.7 \%$ & $2.2 \%$ & $11.5 \%$ & $11.3 \%$ \\
\hline
\end{tabular}




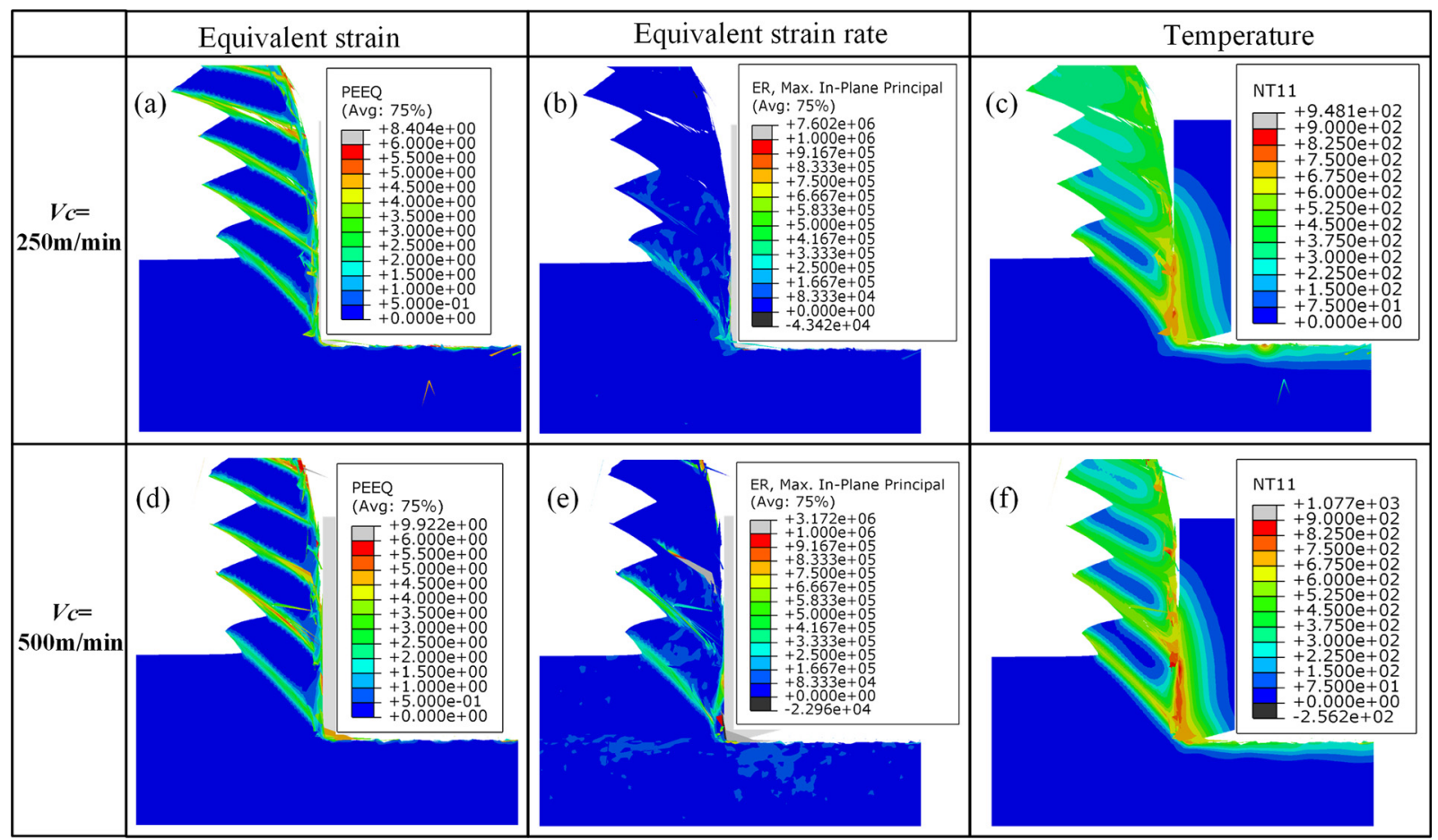

Fig. 13. The simulation results of the equivalent strain ( $a$ and d), equivalent strain rate (b and e) and the temperature (c and f) distributions in chips at a cutting speed of $250 \mathrm{~m} / \mathrm{min}$ and $500 \mathrm{~m} / \mathrm{min}$.

stable because of the dynamic equilibrium between grain nucleation and growth.

Calamaz et al. (2008) proposed a constitutive model with the strain softening behavior. However, the relationship between the grain refinement and constitutive model are not clearly investigated. Due to Eqs. (13) and (20), the CA model including a flow stress equation based on dislocation density evolution can reflect the stress-strain response caused by dislocation density evolution during DRX process. As shown in Fig. 15, The DRX grain nuclei at grain boundaries could result in the decrease of dislocation density, which finally lead to the drop of flow stress. With the continuous increasing of strain, the rise of DRX grains volume fraction and grain size results in the decrease of flow stress due to the decrease of dislocation density.

The flow stress curve and corresponding microstructure morphology

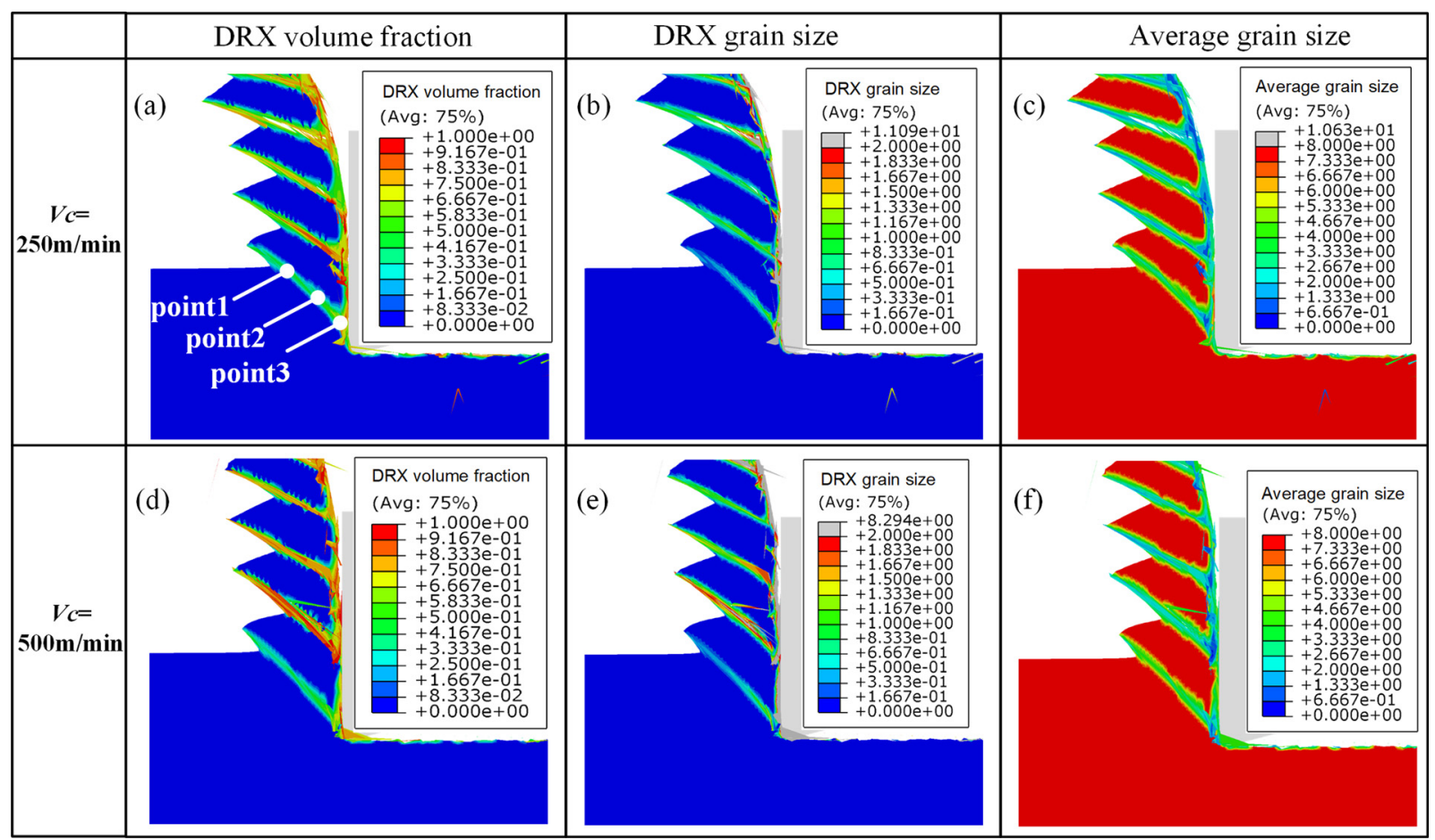

Fig. 14. Simulated results of DRX volume fraction (a and d), DRX grain size ( $\mu \mathrm{m})$ (b and e) and average grain size ( $\mu \mathrm{m})$ (c and f) distributions in chips at a cutting speed of $250 \mathrm{~m} / \mathrm{min}$ and $500 \mathrm{~m} / \mathrm{min}$. 
Table 9

Peak values of strain, strain rate, temperature and DRX kinetics at point 2 in shear band of chips in Fig. 13 and 14.

\begin{tabular}{|c|c|c|c|c|c|c|}
\hline$V_{c}(\mathrm{~m} / \mathrm{min})$ & Strain & Temperature $\left({ }^{\circ} \mathrm{C}\right)$ & Strain rate $(/ \mathrm{s})$ & DRX volume fraction & DRX grain size $(\mu \mathrm{m})$ & Average grain size $(\mu \mathrm{m})$ \\
\hline 250 & 4.5 & 651 & $5 \times 10^{5}$ & 0.82 & 0.93 & 1.33 \\
\hline 500 & 5.3 & 723 & $1.1 \times 10^{6}$ & 0.91 & 1.07 & 1.18 \\
\hline
\end{tabular}

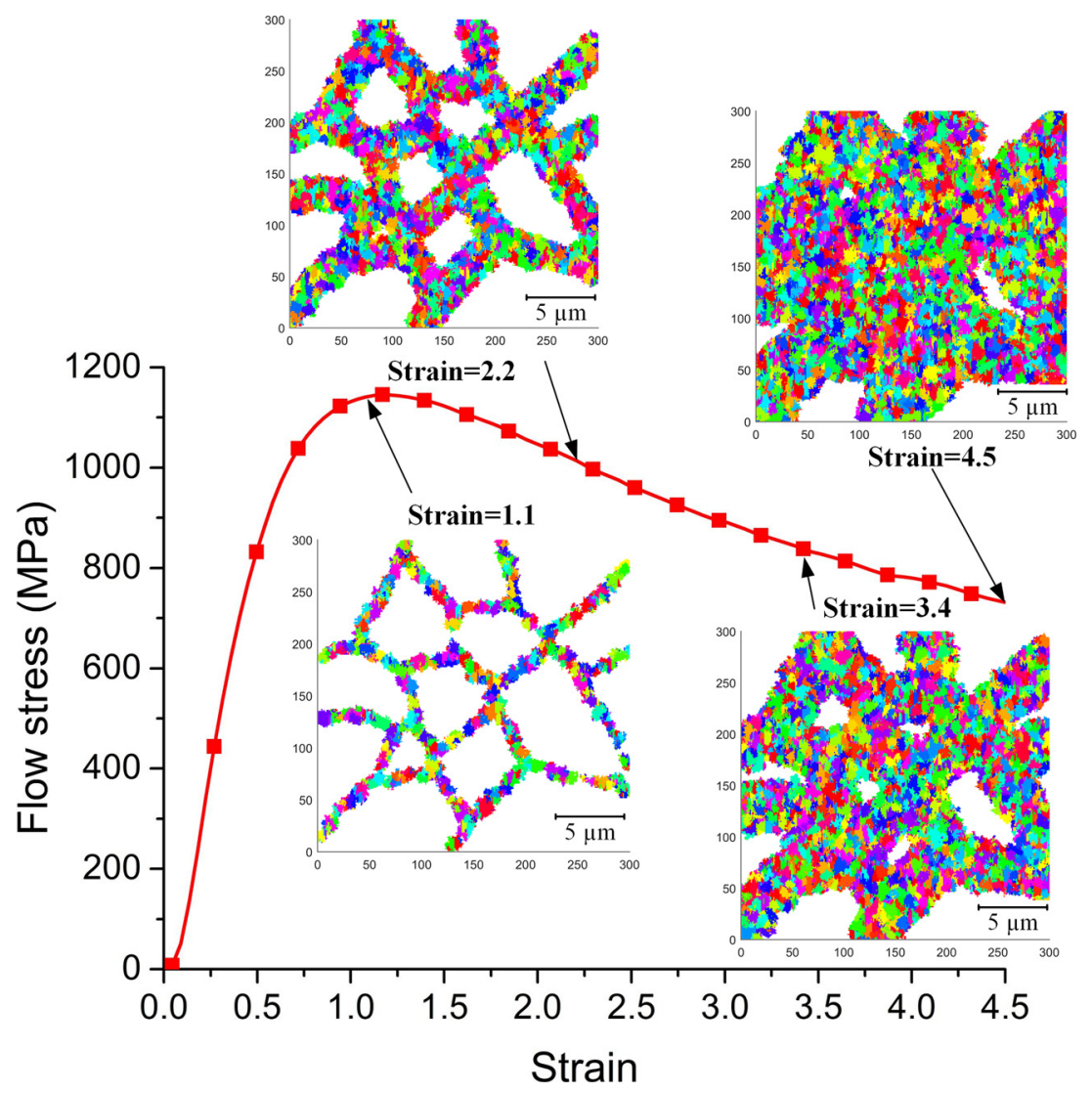

Fig. 15. Stress-strain curve and corresponding microstructure evolution at cutting speed of $250 \mathrm{~m} / \mathrm{min}$.

at a cutting speed of $500 \mathrm{~m} / \mathrm{min}$ are shown in Fig. 16. The flow stress at this cutting speed shows a similar trend with $250 \mathrm{~m} / \mathrm{min}$. However, the peak value of the flow stress at $500 \mathrm{~m} / \mathrm{min}$ is $980 \mathrm{MPa}$, which is lower than $1150 \mathrm{MPa}$ at $250 \mathrm{~m} / \mathrm{min}$ due to thermal softening.

During the DRX process, finer DRX grains were generated and the DRX volume fraction increased, which leads to grain refinement. As shown in Fig. 17, the average grain size starts to decrease rapidly when the strain reaches the critical value of about 0.6 for DRX. Then, the decreasing rate of grain size slow down gradually due to a balance of grain nucleation and growth, which is strongly dependent on the deformation condition. The DRX volume fraction, average grain size and microstructure morphology from this CA simulation will be compared with the experimental observed results.

When refined grains are generated, the physical and mechanical performance of materials would be improved, especially at the level of ultrafine grain size. The effect of grain refinement on microhardness, which is considered corresponding with the strength of the material performance, are also investigated. Picture in Table 10 shows the microhardness indentation performed in the adiabatic shear band of serrated chip, measured using HXD-1000TMC tester under the load of 50 gf for $10 \mathrm{~s}$. As listed in Table 10, The microhardness in adiabatic shear band of serrated chip is higher $(373-400 \mathrm{HV})$ compared with the original material (314 HV in average). According to Hall-Petch theory (Hall, 1951; Petch, 1953), the decreasing of grain size will result in the increasing of microhardness, as shown by the following equation,
$H V=c_{0}+c d^{-1 / 2}$

where $c_{0}$ and $c$ are material constant, $d$ represents the average grain size.

Besides that, when the cutting speed increases from $250 \mathrm{~m} / \mathrm{min}$ to $500 \mathrm{~m} / \mathrm{min}$, the average microhardness increases from $373 \mathrm{HV}$ to $400 \mathrm{HV}$, which mainly results from higher level of grain refinement. Based on the Hall-Petch equation (Hall, 1951; Petch, 1953), the predicted microhardness by FE simulation is shown in Fig. 18. The results show that the predicted results are close to the experimental value, but slightly smaller.

\section{Conclusions}

Grain refinement process induced by DRX during HSM of Ti6Al4V titanium alloy was investigated experimentally and by simulation, in the last case using FE and CA methods. The TANH constitutive model, JC damage model and JMAK grain size prediction model are used in the FE machining model. CA model is developed to show the microstructure evolution at mesoscopic level. This model considers the deformation parameters coming from the FE simulations as input parameters. Finally, the results from FE, CA and experiments are compared to validate the feasibility of combining FE and CA methods to investigate the grain refinement process induced by DRX of Ti6Al4V at high cutting speeds. The main conclusions are summarized as follows: 


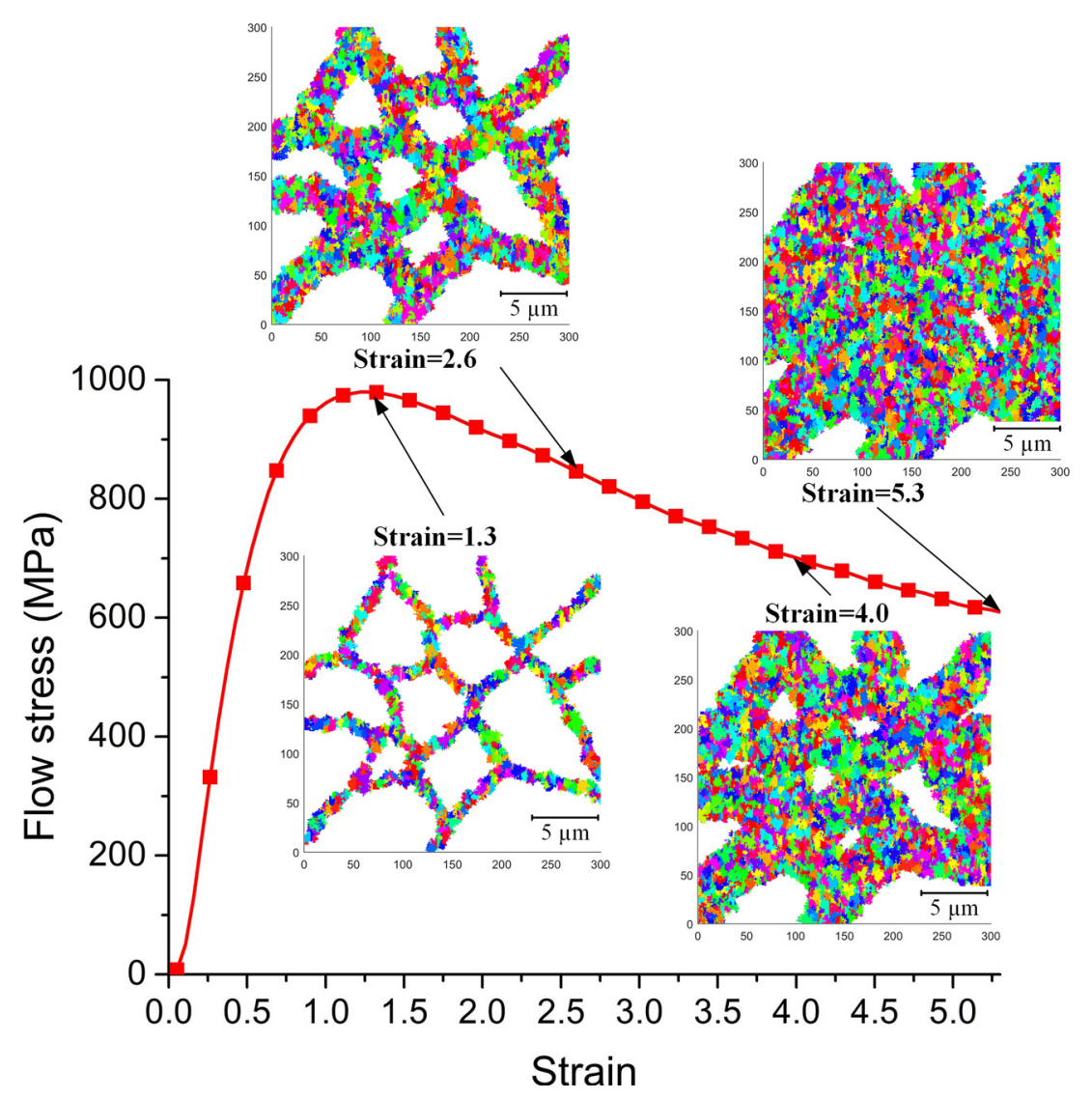

Fig. 16. Stress-strain curve and corresponding microstructure evolution at cutting speed of $500 \mathrm{~m} / \mathrm{min}$.

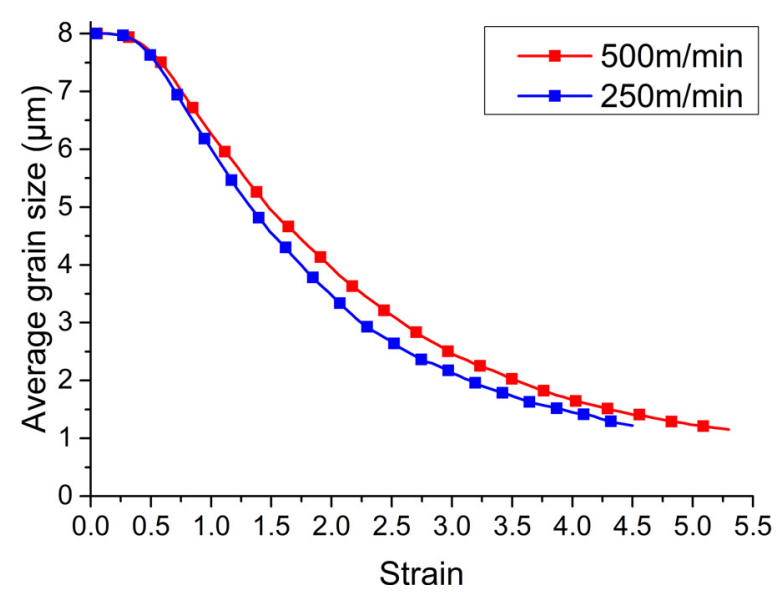

Fig. 17. Evolution of average grain size with increasing strain.

Table 10

Experimental microhardness in adiabatic shear band of serrated chip.

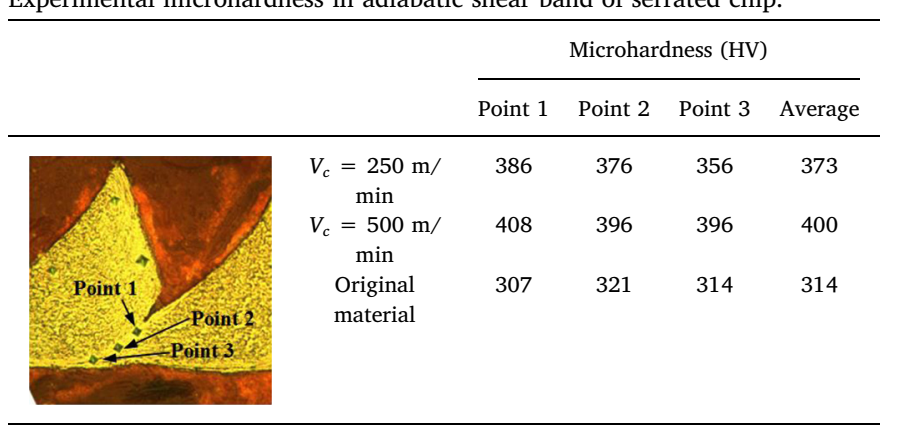

1 The results indicate that FE method is better at displaying the grain size filed distribution in different regions of workpiece in macroscale, while CA method is preferable to visualize the microstructure morphology at a relatively small area. Therefore, the combination of the FE subroutine and CA model can achieve a more comprehensive understanding of the microstructure evolution and its effect on mechanical behavior in cutting process.

2 The field distribution of grain size which is calculated by FE model shows that with cutting speed increasing, the rise of both DRX volume fraction and DRX grain size leads to the slightly decreasing of average grain size, which is induced by higher strain rate and temperature. The recrystallization behavior only occurs in the shear band region and secondary deformation zone, which corresponding to the adiabatic shear of titanium alloy and friction between tool and chip respectively. There are differences of DRX kinetics in different areas along shear band of chips, because higher temperature is benefit for DRX behavior, while higher strain rates enhance grain nucleation and inhibit grain growth. As a result, the decreasing of grain size resulted in the increasing of microhardness.

3 The results of microstructure evolution simulated by CA simulation shows a typical DRX trend of flow stress curve in which the strain softening phenomenon is corresponding to the TANH constitutive model used in FE simulation. When the DRX grain nuclei begin to form at grain boundaries, the increasing rate of flow stress slows down. With the continuous increasing of strain, the rise of DRX grains volume fraction and grain size results in the decrease of flow stress due to the decrease of dislocation density induced by DRX. At the end of the plastic deformation, the continuous increasing of strain leads to DRX grains become dominant, and the average grain size trend to become stable because of the dynamic equilibrium between grain nucleation and growth. 

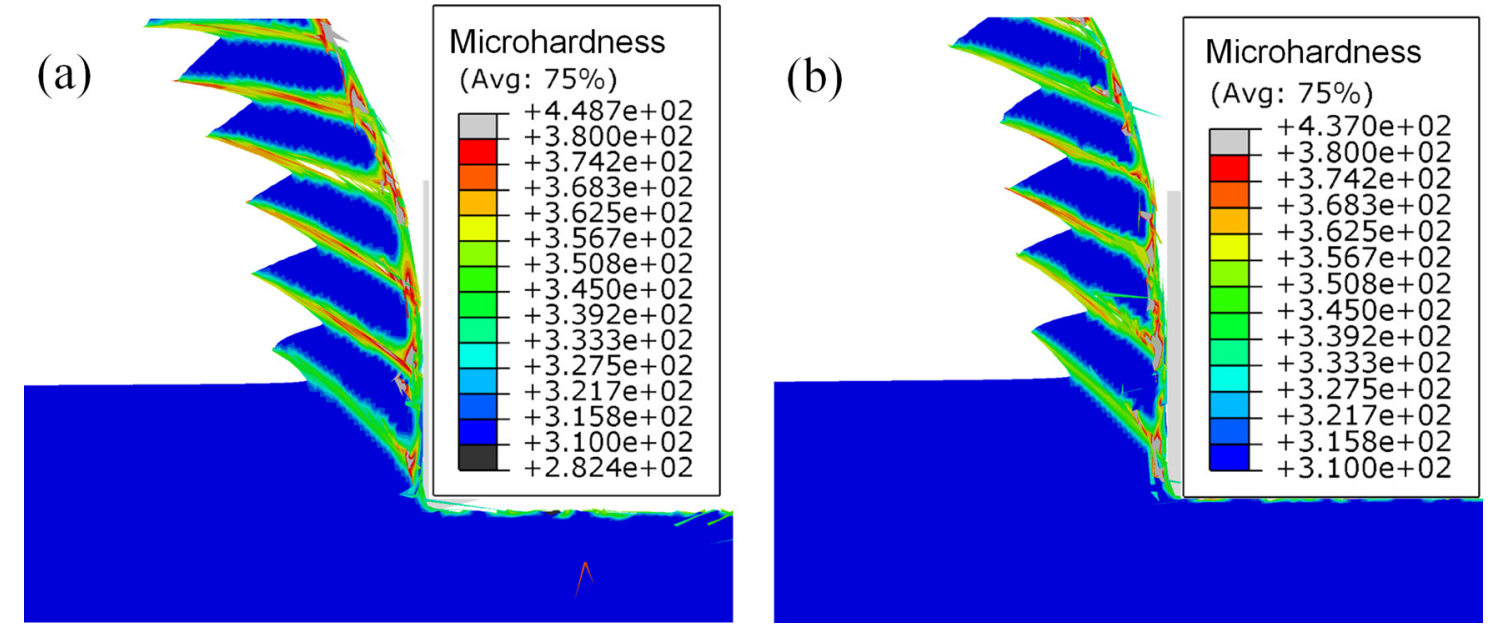

Fig. 18. Simulated microhardness using Hall-Petch equation at cutting speed of (a) $250 \mathrm{~m} / \mathrm{min}$ and (b) $500 \mathrm{~m} / \mathrm{min}$.

It should be noticed that the simulation results have an acceptable error when compared with the experimental results. A more accurate FE and CA model considering the effect of twinning and phase transformation is expected to be developed to predict accurately the grain refinement in multiphase materials.

\section{CRediT authorship contribution statement}

Xiang Xu: Conceptualization, Methodology, Software, Formal analysis, Investigation, Writing - original draft. Jun Zhang: Validation, Investigation, Writing - review \& editing, Supervision, Project administration, Funding acquisition. José Outeiro: Validation, Investigation, Writing - review \& editing, Supervision. Binbin Xu: Software, Formal analysis. Wanhua Zhao: Project administration, Funding acquisition, Writing - review \& editing.

\section{Declaration of Competing Interest}

The authors declare that they have no known competing financial interests or personal relationships that could have appeared to influence the work reported in this paper.

\section{Acknowledgment}

This work was supported by National Natural Science Foundation of China (Grant No. 51675417) and the Shaanxi Science Foundation for Distinguished Young Scholars (2019JC08). The author would also like to acknowledge the financial support from China Scholarship Council (NO. 201906280422).

\section{References}

Andrade, U., Meyers, M.A., Vecchio, K.S., Chokshi, A.H., 1994. Dynamic recrystallization in high-strain, high-strain-rate plastic deformation of copper. Acta Metall. Mater. 42, 3183-3195. https://doi.org/10.1016/0956-7151(94)90417-0.

Arisoy, Y.M., Özel, T., 2015. Prediction of machining induced microstructure in Ti-6Al-4V alloy using 3-D FE-based simulations: effects of tool micro-geometry, coating and cutting conditions. J. Mater. Process. Technol. 220, 1-26. https://doi.org/10.1016/j. jmatprotec.2014.11.002.

Arrazola, P.J., Özel, T., Umbrello, D., Davies, M., Jawahir, I.S., 2013. Recent advances in modelling of metal machining processes. CIRP Ann. Manuf. Technol. 62, 695-718. https://doi.org/10.1016/j.cirp.2013.05.006.

Avrami, M., 1940. Kinetics of phase change. II Transformation-time relations for random distribution of nuclei. J. Chem. Phys. 8, 212-224. https://doi.org/10.1063/1. 1750631.

Bai, Y., Wierzbicki, T., 2008. A new model of metal plasticity and fracture with pressure and Lode dependence. Int. J. Plast. 24, 1071-1096. https://doi.org/10.1016/j.ijplas. 2007.09.004.

Calamaz, M., Coupard, D., Girot, F., 2008. A new material model for 2D numerical simulation of serrated chip formation when machining titanium alloy Ti-6Al-4V. Int. J. Mach. Tools Manuf. 48, 275-288. https://doi.org/10.1016/j.ijmachtools.2007.10. 014.

Courbon, C., Pusavec, F., Dumont, F., Rech, J., Kopac, J., 2014. Influence of cryogenic lubrication on the tribological properties of Ti6Al4V and Inconel 718 alloys under extreme contact conditions. Lubr. Sci. 26, 315-326. https://doi.org/10.1002/1s. 1254.

Dargusch, M.S., Sun, S., Kim, J.W., Li, T., Trimby, P., Cairney, J., 2018. Effect of tool wear evolution on chip formation during dry machining of Ti-6Al-4V alloy. Int. J. Mach. Tools Manuf. 126, 13-17. https://doi.org/10.1016/j.ijmachtools.2017.12.003.

Davim, J.P., Maranhão, C., Jackson, M.J., Cabral, G., Grácio, J., 2008. FEM analysis in high speed machining of aluminium alloy (Al7075-0) using polycrystalline diamond (PCD) and cemented carbide (K10) cutting tools. Int. J. Adv. Manuf. Technol. 39, 1093-1100. https://doi.org/10.1007/s00170-007-1299-y.

Denguir, L.A., Outeiro, J.C., Fromentin, G., Vignal, V., Besnard, R., 2017. A physicalbased constitutive model for surface integrity prediction in machining of OFHC copper. J. Mater. Process. Technol. 248, 143-160. https://doi.org/10.1016/j. jmatprotec.2017.05.009.

Ding, R., Guo, Z.X., 2001. Coupled quantitative simulation of microstructural evolution and plastic flow during dynamic recrystallization. Acta Mater. 49, 3163-3175. https://doi.org/10.1016/S1359-6454(01)00233-6.

Ding, R., Guo, Z.X., 2002. Microstructural modelling of dynamic recrystallisation using an extended cellular automaton approach. Comput. Mater. Sci. https://doi.org/10. 1016/S0927-0256(01)00211-7.

Ding, R., Guo, Z.X., 2004. Microstructural evolution of a Ti-6Al-4V alloy during $\beta$-phase processing: experimental and simulative investigations. Mater. Sci. Eng. A 365, 172-179. https://doi.org/10.1016/j.msea.2003.09.024.

Ding, H., Shen, N., Shin, Y.C., 2011. Modeling of grain refinement in aluminum and copper subjected to cutting. Comput. Mater. Sci. 50, 3016-3025. https://doi.org/10. 1016/j.commatsci.2011.05.020.

Duan, C.Z., Zhang, L.C., 2012. Adiabatic shear banding in AISI 1045 steel during high speed machining: mechanisms of microstructural evolution. Mater. Sci. Eng. A 532, 111-119. https://doi.org/10.1016/j.msea.2011.10.071.

Estrin, Y., Kim, H.S., 2007. Modelling microstructure evolution toward ultrafine crystallinity produced by severe plastic deformation. J. Mater. Sci. 42, 1512-1516. https://doi.org/10.1007/s10853-006-1282-2.

Fanfoni, M., Tomellini, M., 1998. The Johnson-Mehl-Avrami-Kolmogorov model: A brief review. Nuovo Cim. della Soc. Ital. di Fis. D - Condens. Matter, At. Mol. Chem. Physics, Biophys. 20, 1171-1182. https://doi.org/10.1007/BF03185527.

Goetz, R.L., Seetharaman, V., 1998. Modeling dynamic recrystallization using cellular automata. Scr. Mater. 38, 405-413. https://doi.org/10.1016/S1359-6462(97) 00500-9.

Guo, Y., Saldana, C., Dale Compton, W., Chandrasekar, S., 2011. Controlling deformation and microstructure on machined surfaces. Acta Mater. 59, 4538-4547. https://doi. org/10.1016/j.actamat.2011.03.076.

Hall, E.O., 1951. The deformation and ageing of mild steel: II Characteristics of the Lüders deformation. Proc. Phys. Soc. Sect. B 64, 742-747. https://doi.org/10.1088/03701301/64/9/302.

He, Y., Ding, H., Liu, L., Shin, K., 2006. Computer simulation of 2D grain growth using a cellular automata model based on the lowest energy principle. Mater. Sci. Eng. A 429, 236-246. https://doi.org/10.1016/j.msea.2006.05.070.

Huang, K., Logé, R.E., 2016. A review of dynamic recrystallization phenomena in metallic materials. Mater. Des. 111, 548-574. https://doi.org/10.1016/j.matdes.2016.09. 012.

Imbrogno, S., Rinaldi, S., Umbrello, D., Filice, L., Franchi, R., Del Prete, A., 2018. A physically based constitutive model for predicting the surface integrity in machining of Waspaloy. Mater. Des. 152, 140-155. https://doi.org/10.1016/j.matdes.2018.04. 069.

Johnson, G.R., Cook, W.H., 1985. Fracture characteristics of three metals subjected to various strains, strain rates, temperatures and pressures. Eng. Fract. Mech. 21, 31-48. 
https://doi.org/10.1016/0013-7944(85)90052-9.

Kugler, G., Turk, R., 2004. Modeling the dynamic recrystallization under multi-stage hot deformation. Acta Mater. 52, 4659-4668. https://doi.org/10.1016/j.actamat.2004. 06.022

Lee, W.S., Lin, C.F., 1998. High-temperature deformation behaviour of Ti6A14V alloy evaluated by high strain-rate compression tests. J. Mater. Process. Technol. 75, 127-136. https://doi.org/10.1016/S0924-0136(97)00302-6.

Liao, Z., Polyakov, M., Diaz, O.G., Axinte, D., Mohanty, G., Maeder, X., Michler, J., Hardy, M., 2019. Grain refinement mechanism of nickel-based superalloy by severe plastic deformation - Mechanical machining case. Acta Mater. 180, 2-14. https://doi.org/ 10.1016/j.actamat.2019.08.059.

Littlewood, P.D., Britton, T.B., Wilkinson, A.J., 2011. Geometrically necessary dislocation density distributions in Ti-6Al-4V deformed in tension. Acta Mater. 59, 6489-6500. https://doi.org/10.1016/j.actamat.2011.07.016.

Liu, R., Salahshoor, M., Melkote, S.N., Marusich, T., 2015. A unified material model in cluding dislocation drag and its application to simulation of orthogonal cutting of OFHC Copper. J. Mater. Process. Technol. 216, 328-338. https://doi.org/10.1016/j. jmatprotec.2014.09.021.

M'Saoubi, R., Ryde, L., 2005. Application of the EBSD technique for the characterisation of deformation zones in metal cutting. Mater. Sci. Eng. A 405, 339-349. https://doi. org/10.1016/j.msea.2005.06.002.

Mabrouki, T., Girardin, F., Asad, M., Rigal, J.F., 2008. Numerical and experimental study of dry cutting for an aeronautic aluminium alloy (A2024-T351). Int. J. Mach. Tools Manuf. 48, 1187-1197. https://doi.org/10.1016/j.ijmachtools.2008.03.013.

Mecking, H., Kocks, U.F., 1981. Kinetics of flow and strain-hardening. Acta Metall. 29, 1865-1875. https://doi.org/10.1016/0001-6160(81)90112-7.

Melkote, S.N., Grzesik, W., Outeiro, J., Rech, J., Schulze, V., Attia, H., Arrazola, P.J., M'Saoubi, R., Saldana, C., 2017. Advances in material and friction data for modelling of metal machining. CIRP Ann. Manuf. Technol. 66, 731-754. https://doi.org/10. 1016/j.cirp.2017.05.002.

Miguélez, M.H., Soldani, X., Molinari, A., 2013. Analysis of adiabatic shear banding in orthogonal cutting of Ti alloy. Int. J. Mech. Sci. 75, 212-222. https://doi.org/10. 1016/j.ijmecsci.2013.06.011.

Molinari, A., Musquar, C., Sutter, G., 2002. Adiabatic shear banding in high speed machining of Ti-6Al-4V: experiments and modeling. Int. J. Plast. 18, 443-459. https:// doi.org/10.1016/S0749-6419(01)00003-1.

Pan, Z., Liang, S.Y., Garmestani, H., Shih, D.S., 2016. Prediction of machining-induced phase transformation and grain growth of Ti-6Al-4 V alloy. Int. J. Adv. Manuf. Technol. 87, 859-866. https://doi.org/10.1007/s00170-016-8497-4.

Pan, Z., Feng, Y., Liang, S.Y., 2017. Material microstructure affected machining: a review. Manuf. Rev. (Les Ulis) 4, 5. https://doi.org/10.1051/mfreview/2017004.

Petch, N.J., 1953. The cleavage strength of polycrystals. J. Iron Steel Inst. 174, 25-28.

Qian, M., Guo, Z.X., 2004. Cellular automata simulation of microstructural evolution during dynamic recrystallization of an HY-100 steel. Mater. Sci. Eng. A 365, 180-185. https://doi.org/10.1016/j.msea.2003.09.025

Roberts, W., Ahlblom, B., 1978. A nucleation criterion for dynamic recrystallization during hot working. Acta Metall. 26, 801-813. https://doi.org/10.1016/00016160(78)90030-5.

Rotella, G., Dillon, O.W., Umbrello, D., Settineri, L., Jawahir, I.S., 2013. Finite element modeling of microstructural changes in turning of AA7075-T651 Alloy. J. Manuf. Process. 15, 87-95. https://doi.org/10.1016/j.jmapro.2012.09.005.

Shen, N., Samanta, A., Ding, H., 2017. Microstructure simulations for orthogonal cutting via a cellular automaton model. Procedia Cirp 58, 543-548. https://doi.org/10. 1016/j.procir.2017.03.264.

Sima, M., Özel, T., 2010. Modified material constitutive models for serrated chip formation simulations and experimental validation in machining of titanium alloy Ti6Al-4V. Int. J. Mach. Tools Manuf. 50, 943-960. https://doi.org/10.1016/j. ijmachtools.2010.08.004

Song, K.J., Dong, Z.B., Fang, K., Zhan, X.H., Wei, Y.H., 2014. Cellular automaton modelling of dynamic recrystallisation microstructure evolution during friction stir welding of titanium alloy. Mater. Sci. Technol. (United Kingdom) 30, 700-711. https://doi.org/10.1179/1743284713Y.0000000389.

Stüwe, H.P., Ortner, B.B., 1974. Recrystallization in hot working and creep. Met. Sci. 8 , 161-167. https://doi.org/10.1179/msc.1974.8.1.161.

Sun, J., Guo, Y.B., 2009. Material flow stress and failure in multiscale machining titanium alloy Ti-6Al-4V. Int. J. Adv. Manuf. Technol. 41, 651-659. https://doi.org/10.1007/ s00170-008-1521-6.

Sutter, G., List, G., 2013. Very high speed cutting of Ti-6Al-4V titanium alloy - Change in morphology and mechanism of chip formation. Int. J. Mach. Tools Manuf. 66, 37-43. https://doi.org/10.1016/j.ijmachtools.2012.11.004.

Wang, Q., Liu, Z., Wang, B., Song, Q., Wan, Y., 2016. Evolutions of grain size and microhardness during chip formation and machined surface generation for Ti-6Al-4V in high-speed machining. Int. J. Adv. Manuf. Technol. 82, 1725-1736. https://doi.org/ 10.1007/s00170-015-7508-1.

Xu, X., Zhang, J., Liu, H., He, Y., Zhao, W., 2019. Grain refinement mechanism under high strain-rate deformation in machined surface during high speed machining Ti6Al4V. Mater. Sci. Eng. A 752, 167-179. https://doi.org/10.1016/j.msea.2019.03.011.

Zener, C., Hollomon, J.H., 1944. Effect of strain rate upon plastic flow of steel. J. Appl. Phys. 15, 22-32. https://doi.org/10.1063/1.1707363.

Zerilli, F.J., Armstrong, R.W., 1987. Dislocation-mechanics-based constitutive relations for material dynamics calculations. J. Appl. Phys. 61, 1816-1825. https://doi.org/10 1063/1.338024.

Zhang, Y., Mabrouki, T., Nelias, D., Gong, Y., 2011. FE-model for Titanium alloy (Ti-6Al$4 \mathrm{~V})$ cutting based on the identification of limiting shear stress at tool-chip interface. Int. J. Mater. Form. 4, 11-23. https://doi.org/10.1007/s12289-010-0986-7.

Zorev, N.N., 1963. Interrelationship between shear processes occurring along tool face and on shear plane in metal cutting. Roceedings Int. Res. Prod. Eng. Conf. 42-49. 